\title{
EXCAVACIONES EN TIERRADENTRO
}

[El Tablón, El Volador, Cementerio de Segovia, El Rodeo y El Marne].

$$
\text { Por }
$$

STANLEY VeRNON LONG * $(\dagger)$

$\mathrm{Y}$

JUAN A. YÁNGÜEZ B.

* Obra póstuma. 


\section{$P R E F A C I O$}

El presente informe tiene como objeto salvar en parte el material cultural (cerámico) del Proyecto Arqueológico de Tierradentro, dirigido por el doctor Stanley Vernon Long desde junio hasta diciembre de 1967, fecha ésta en que falleció.

A partir de marzo de 1968 se me encomendó la continuación de este Proyecto ya que estaba familiarizado con los sitios y el material, en calidad de asistente que fui en dicho Proyecto.

Tierradentro significaba mucho para este amigo y profesor, motivo por el cual aún sabiendo de los problemas que conlleva este material, acepté. He consultado con varias personas sobre esta cerámica, me han dado excelentes sugerencias pero no las puedo aplicar a Tierradentro, i. e. análisis basado en la decoración, evolución o formas de las vasijas.

La evolución no existe y pocas son las formas que se han podido reconstruír, pues de los bordes sólo existe la parte superior con la cual es difícil figurar todas las formas con excepción de algunos fragmentos con parte del cuerpo que se pudieron recuperar. La mayoría de la cerámica es esencialmente del tipo Roja Sencilla (otros nombres pueden ser café, carmelita, etc.).

En vista de todo este problema, presento una tipología a la usanza tradicional en la arqueología esperando que ella sea de alguna utilidad para quienes investiguen en la región así como los varios anexos que he incluido como guía.

Para las comparaciones me he servido de criterios tales como algunas formas de vasijas, vertederas, asas, bordes y algunos 'tipos' como cerámica modelada acanalada y crema sencilla que pueden dar alguna idea de posibles relaciones.

Toda la responsabilidad del presente informe debe recaer solamente sobre mi, ya que solo yo puedo responder cualquier pregunta sobre este material. 
Solo deseo que se puedan llevar a cabo más investigaciones y así poder resolver en parte las problemáticas que surgen a través del presente texto. Este trabajo es el primero que trata sobre sitios de habitación y espero que no sea el último.

En nombre del doctor Long y del mío, deseamos expresar nuestros agradecimientos a su esposa, doña Lutie Beth Long, quien supervisó el lavado y reembolso del material cultural durante nuestra estadía en el terreno; a los doctores Manuel José Casas Manrique y Francisco Márquez Yánez, Director y Subdirector, respectivamente, del Instituto Colombiano de Antropología, quienes nos brindaron su irrestricta colaboración concediéndonos permiso para excavar, alojamiento en el Hotel del Parque Arqueológico de Tierradentro, utilización de las bestias de carga e instrumentos de excavación; a don Teófilo Grajales, Administrador del Parque; a don Juan Carvajal Agudelo, maestro de obra del Parque; al señor Alcalde de Inzá; a las autoridades eclesiásticas de Inzá y San Andrés de Pisimbalá; al Jefe del Destacamento del Ejército Nacional acantonado en El Rodeo; a nuestros trabajadores; a los Directivos de la Universidad de los Andes; a los doctores Alicia y Gerardo ReichelDolmatoff, José de Recasens, Segundo Bermal y Juan A. Villamarín. A la señora Ana de Yazo, Giovanni Castro Victoria, Jacques Aghion y demás personas que se mostraron interesadas en nuestro proyecto. Un agradecimiento muy especial al doctor Johannes Wilbert, Director del Latin American Center de la Universidad de California, Los Angeles, quien hizo posible la continuación del análisis del material cerámico de Tierradentro gracias al fondo que designó para este particular.

Para todos,

Mil gracias,

JUAN ANTONIO YÁNGÜEZ BERNAL.

Marzo de 1969.

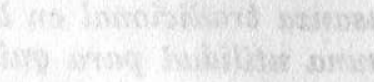

M A P A S :

1. Mapa de Tierradentro en el cual se localizan especialmente los sitios excavados por nosotros. (Dibujo de S. V. Long)

2. Mapas de curvas de nivel. (S. V. Long.).

a) El Tablón.

b) El Volador.

c) Cementerio de Segovia.

d) El Rodeo.

e) El Marne.

(Copias hechas por los Arq. Carlos Morales H., Jacques Aghion y Juan A. Yángüez).

A E R O F O TO :

Aerofoto de una sección de Tierradentro incluyendo nuestros sitios y el pueblo de San Andrés de Pisimbalá.

L A M I N A S :

1. 1. Sección del valle del Marne, Tierradentro.

2. Entrada de la tumba número 2 excavada en el Cementerio de Segovia.

3. Vista parcial del montículo del Cementerio de Segovia. Al fondo se observan las dos tumbas a cuyos lados se encontró la tumba número 2.

4. Perfil de la pared Este del pozo 7. El Tablón.

5. Pozo número 9 excavado por estratos naturales. El Tablón.

. La primera capa natural ya ha sido removida, el resto pertenece al segundo estrato, uniforme.

2. 1. Las tres figuras superiores muestran la forma en que fueron encontradas las vasijas dentro de la tumba número 2. Sepultadas bajo una gruesa capa de greda, la cual cubria la tumba hasta la mitad. Los nichos muestran la altura del depósito de greda.

2. Dibujo inferior izquierdo: dibujo de la forma en que se encontraron las vasijas.

3. Fotos, inferior derecha: vasija pequeña con relleno de pasta blanca, encontrada en la tumba número 2, en Segovia.

3. 1. Vasija encontrada dentro de la tumba número 1, en Segovia. 2, 4, 5 Son del museo del Parque Arqueológico de Tierradentro, 
pero iruales a las nuestras encontradas en la tumba número 2 . $3,6,7,8,9,10,11,12$ Vasijas de la tumba número 2, Segovia, Tierradentro.

4. Restos humanos encontrados en las urnas funerarias de la tumba número 2, Segovia, Tierradentro.

5. Vasijas procedentes de Pedregal y Segovia. Actualmente se en cuentran en el Museo Arqueológico del Parque Arqueológico de Tierradentro.

D I B U J O S :

Dibujo de la forma de la tumba número 2, Segovia, Tierradentro. Bordes, cerámica decorada, volante de huso y un fragmento bicromo de El Tablón, Volador, Marne y Rodeo, Tierradentro.

Reconstrucciones de algunas vasijas encontradas en nuestras excavaciones.

\section{INDICE DE LOS ANEXOS}

I. Matriz de los pozos.

II. Medida de los perfiles de los pozos.

III. Descripción de la cerámica de los sitios de habitación.

IV. Cuadro de distribución de tipos cerámicos.

V. Descripción de las tumbas número 1 y número 2.

\section{N T R O D U C C I O N}

De todos son conocidas las innumerables problemáticas que ofrece la arqueología colombiana, dentro y fuera del país.

Muchos son los arqueólogos que han trabajado en Colombia, en regiones tales como la Sierra Nevada de Santa Marta, Sinú, Costa Pnelfica, Chocó, Nariño, San Agustín, Tierradentro y en la Altiplunicie del Reino (Cundinamarca y Boyacá), con el fin de incrementar el conocimiento arqueológico del país y así poder tratar de resolver algunas problemáticas presentes; sin embargo ha sido una verdadera lástima que muchos de ellos no se hayan preocupado por hncer, i. e. excavaciones estratigráficas bien controladas o por excavar sitios de habitación o por presentar un informe útil y con verdadero valor científico. Así pues, vemos para algunas zonas, gran cuntidad de literatura pero que no pasa de ser esto e inclusive hipótesis sobre orígenes, emplazamiento, migración y relaciones de algunas culturas sin base científica o prueba válida alguna.

Un ejemplo que nos interesa, es el de Tierradentro (véase mapa de T. A.) a quien se le ha creado un origen agustiniano basándose casi exclusivamente en comparaciones estilísticas de la estatuaria lítica y formas de entierros en tumbas, y aún más, una cronología y etapa de desarrollo y evolución cultural sin pruebas fehacientes pues todavía falta mucho por hacer en esta zona; para San Agustín, zona contigua a Tierradentro, también existen muchísimas lagunas.

Para esta última, en 1966, el doctor Reichel-Dolmatoff dirigió un proyecto arqueológico, auspiciado por la Universidad de los Andes, Bogotá, con miras de hacer excavaciones estratigráficas en sitios de habitación humana para tratar de establecer una cronología y comparaciones culturales de la región, con resultados muy positivos.

Como se ha hablado y escrito mucho sobre las relaciones entre San Agustín y Tierradentro, y teniendo el material arqueológico de 
San Agustín a mano, el cual podría facilitar las comparaciones con Tierradentro, el doctor S. V. Long propuso un proyecto de investigación arqueológica a esta zona, nuevamente auspiciado por la Universidad de los Andes, el cual se realizó entre el 12 de junio y el 15 de agosto de 1967, lográndose obtener material cultural de sitios de habitación, de sepulcros y superficiales así como el descubrimiento y excavación de un nuevo sepulcro en Segovia (sitio famoso en la literatura por el gran número de cámaras subterráneas, decoradas con motivos geométricos en blanco, rojo, negro y amarillo y con escaleras en forma de espiral). También pudimos obtener muestras de carbón y huesos humanos tanto de los sitios de habitación como de algunas de las tumbas ya excavadas.

Sin embargo, es una verdadera lástima que no podamos dar fechas de C-14, como era nuestro propósito, puesto que todavía no se han recibido los resultados de las muestras enviadas en diciembre de 1967 al Institute of Geophysics and Planetary Physics de la Universidad de California, Los Angeles (las cuales pensábamos se encontraban todavía en proceso de análisis pero, aparentemente, según nuestra correspondencia con el antes mencionado Instituto, dichas muestras se han perdido). No obstante han prometido indagar sobre el particular y esperamos resulte algo positivo y podamos tener tales fechas.

\section{AMBIENTE GEOGRAFICO}

Tierradentro, como su nombre lo indica, es una región ubicada en el 'interior', es decir, en el medio del país, en la Cordillera Central.

La Cordillera Central es uno de los tres ramales resultantes de la división súbita de la Cordillera de los Andes al norte del Ecuador. Los otros dos ramales son la Cordillera Oriental y la Occidental.

La Cordillera Oriental tiene una altitud promedia de 2.000 metros y se considera la más ancha de las tres. Forma varias mesetas altas entre las cuales está la de Bogotá. Esta cordillera se divide en otros dos ramales, uno de los cuales continúa hacia el Caribe y termina cerca de la Península de la Guajira y es la Sierra de Perijá. El otro ramal de esta cordillera, continúa en Venezuela con el nombre de Cordillera de Mérida. Entre la Cordillera Oriental y la Cen- tral, corre el río Magdalena, el cual se va ensanchando hasta obtener su máxima amplitud en la costa norte colombiana.

La Cordillera Central, entre los valles del río Magdalena y el Cauca, es la más alta, con una altitud promedia de 3.000 metros, pero va reduciendo su altura en su parte norte, donde forma la meseta de Antioquia y luego se divide en pequeños ramales hasta desaparecer en las tierras bajas de la Costa Caribe. Está culminada por volcanes en la parte sur. El cañón del Cauca está bien marcado entre Cartago y Cali (700 metros de elevación) ; luego asciende abruptamente hasta los 1.000 metros hacia Popayán.

Finalmente, el valle del Cauca, que mide aproximadamente 15 kms. de ancho cerca de Popayán; la Cordillera Occidental es la más baja y corta. Al norte de Cabo Corriente y a lo largo de la Costa Pacífica, encontramos la Serranía del Baudó, la cual sigue hasta el Istmo de Panamá. Limitado por la Cordillera Occidental y la Serranía del Baudó, está el río Atrato que desemboca en el Golfo de Urabá, también la Costa Caribe.

Esta partición de los Andes ha creado nichos ecológicos de especial importancia para los habitantes de estas zonas.

A una altura de 3.000 metros, las tierras frías y páramos proveen excelente pasto y buenas condiciones para el cultivo de la papa. Las sabanas a una altura de 2.500 metros, especialmente en la cordillera Oriental, son importantes sitios agrícolas, generalmente sembrados de maíz. Las tierras bajas del Magdalena y Cauca producen productos tropicales.

La estructura tectónica de Colombia da origen a una gran diversidad de climas. A una distancia muy corta, uno pasa de la selva tropical lluviosa a la sabana tropical, al desierto, y de la estepa a las tierras altas húmedas.

Colombia tiene una condición física extremadamente contrastante en Sur América así como una posición estratégica con respecto a la comunicación continental; es un país ventajoso para el desarrollo cultural y el paso obligado para los primeros habitantes del continente americano y puente de comunicación-migración terrestre.

Con respecto a nuestra zona, geográficamente, Tierradentro está localizada entre el Volcán Puracé $\left(2^{\circ}-3^{\circ}\right.$ long. W del meridiano de Bogotá, y $2^{\circ}-3^{\circ}$ de latitud) y el Nevado del Huila $\left(2^{\circ}\right.$ long. W. del Meridiano de Bogotá y $3^{\circ}$ de latitud). El principal río de la región es el Páez $\left(1^{\circ} 24^{\prime}, 2^{\circ}\right.$ long. W. del meridiano de Bogotá y $2^{\circ}$ $25^{\prime}, 3^{\circ}$ latitud), el cual se extiende casi a lo largo de toda la región. El y sus tributarios, los ríos Ullucos, Negro de Narváez, Mora, 
La Plata, Kukiyú, y otros (iguales coordenadas que las del Páez) y cerca de 49 cursos de agua han disectado las montañas en un sinnúmero de pequeños valles, los cuales están cubiertos de una densa floresta, monte, herbazales, de acuerdo con la elevación, vertiente y el grado de explotación humana. El doctor Bernal $(1953: 281)$ ha descrito esta zona en una forma concisa, exacta y poética:

En el Departamento del Cauca y en su noreste, como una punta de lanza que se enclava en el Departamento del Huila, se halla la región de Tierradentro formada por los numerosos contrafuertes orientales de la Cordillera Central. Tiene la figura de un triangulo formado por las divisorias de aguas de las cuencas hidrograficas de los rio Páez y Yaguará al oriente y la Plata y Páez al Sur. Hacia el occidente, como espina dorsal, levantase la Cordillera Central en la que sobresalen los páramos de Guanacas (3518 metros), de Las Delicias (3750 metros) y de Moras (3670 metros). Como coloso gigantesco y dominando el vértice de esta zona geométrica encuéntrase hacia e norte el nevado del Huila ( 5750 metros), el más alto de Colombia se exceptúa la Sierra Nevada de Santa Marta.

El clima oscila entre templado y templado-frío, de acuerdo con los factores geográficos. Si excluímos la zona paramuna (de los páramos), podemos establecer cuatro zonas de vegetación:

1. Bosque muy húmedo subtropical (bmh - ST)

Temperatura media: $17^{\circ}$ a $24^{\circ} \mathrm{C}$

Precipitación media anual: 2.000 a $4.000 \mathrm{mms}$.

Altitud: 1.000 a 2.000 metros.

Incluye las vertientes bajas de los valles ribereños en los cuales están ubicados los pueblos de Avirama, Páez, Inzá, El Rodeo y la Hacienda El Marne.

2. Bosque muy húmedo montano bajo (bmh-MB)

Temperatura media: 12 a a $188^{\circ} \mathrm{C}$. $4.000 \mathrm{mms}$.

Altitud: 2.000 a 2.500 metros.

En esta zona están los pueblos de San Andrés de Pisimbalá y Suin.

3. Bosque pluvial montano bajo (bp-MB).

Temperatura media: $12 \%$ a $18 \% \mathrm{C}$.

Precipitación media anual: mayor de $4.000 \mathrm{mms}$.

Altitud: 2.500 a 3.500 metros.

Pueblo: Mosoco.

4. Bosque pluvial montano (bp-M).

Temperatura media: 6 ? a 12 \% $\mathrm{C}$.

Precipitación media anual: 2.000 a $4.000 \mathrm{mms}$.

Altitud: Incluye las partes altas de la cordillera entre los 3.500

a 4.000 metros con excepción de los páramos que oscilan entre los 4.000 y 4.500 metros.

En esta zona no encontramos ningún establecimiento humano.

(Formaciones vegetales de Colombia, 1963; DANE: División Zo-

1965; Burr, 1937 -1938; Sauer, 1950; Atlas de Colombia, 1967).

De estas cuatro zonas de vegetación de Tierradentro, solo nos interesan dos: bmh-ST y bp-ST. El primero se distribuye amplia- mente por las vertientes de las Cordilleras Andinas, constituyendo en parte la faja cafetera de Colombia. La situación de estos bosques en las vertientes de las cordilleras se debe a la gran cantidad de lluvias, debidas a efectos orográficos. Al ascender los vientos de los valles, las masas de aire húmedo sufren enfriamientos que provocan fuertes aguaceros. La precipitación es superior al agua que la vegetación puede utilizar y también al agua que el suelo puede utilizar provocando en esta forma depósitos en la superficie, gran humedad, erosión, lavado del suelo, etc., trayendo como consecuencia la esterilización rápida del terreno.

Los terrenos son en su mayoría de una topografía montañosa (véase aerofoto de T. A.) intercalada con pequeños valles planos o con leves ondulaciones del terreno, como los son los de El Marne y El Rodeo.

Predominan los cañones profundos y los estrechos ríos caudalosos. El sistema fluvial es complicado por los numerosos ríos menores y quebradas que se desprenden de los Andes en todas las direcciones.

En su estado original es un bosque alto, siempre verde, con algunas epífitas y quiches sobre las ramas. En las áreas de precipitación menor y en donde se tuvieron buenos suelos, estos bosques originales desaparecidos y fueron sustituídos por cultivos y pastos. Quedan todavía bosques naturales de esta formación en aquellas zonas de alta precipitación, pero poco a poco van siendo talados para incorporar esos terrenos a diversos sistemas agrícolas. La falta de vías de comunicación ha protegido la zona con bosques naturales.

Gran parte de la zona cafetera de Colombia se encuentra localizada, como ya se dijo antes, en este tipo de zona. Muchas áreas se encuentran sembradas de caña de azúcar y otras utilizadas como potreros para ganado.

El otro tipo de zona de vegetación se extiende por la vertiente oriental de la Cordillera Oriental y por la vertiente occidental de la Cordillera Occidental.

Llueve generalmente todos los meses del año, el ambiente es húmedo y se presentan frecuentemente nubes y neblinas. Al igual que el bmh - ST, hay un sobrante de agua que no puede ser utilizada por las plantas o por el suelo.

Esta alta pluviosidad se explica en parte por el efecto de las Cordilleras Oriental y Occidental, pues éstas detienen las masas de aire húmedo procedentes de los Llanos Orientales y de la Cuenca Pacífica, provocando su condensación y luego una precipitación abundante sobre las laderas. 
También la topografía es parecida a la del bmh - ST. Los árboles se cubren de quiches, epífitas, musgos y lianas y sus troncos, en gran parte, con musgos, líquenes y trepadoras.

En algunas partes entre los 2.000 y $4.000 \mathrm{mms}$. de lluvia, hay núcleos humanos quienes después de cortar el bosque, establecen algunos cultivos tales como caña y maíz, por unos pocos años, ya que el lavado intenso a que están sometidos estos terrenos, los esteriliza rápidamente.

Extensos bosques ya no existen. Los gruesos y espesos bosques han sido talados sistemáticamente por indios y por colonos, de tal manera que éstos se encuentran actualmente hacia las escarpadas breñas de la Cordillera Central y las hoyas hidrográficas de los ríos Símbola y Negro de Narváez. En las vegas y pequeños valles de las quebradas y ríos se encuentra una vigorosa vegetación, en su mayor parte resultado cultural, pues ha sido sembrada para sombrío de los numerosos cafetales.

En las lomas y altiplanicies, los arbustos y matorrales son comunes en tanto que en los declives los herbazales presentan su opulento verdor en el invierno y la coloración pardo-amarillenta en los veranos. Las tierras de labor se preparan con machete y fuego. La quema es un hábito de nativos y colonos y llega hasta tal punto que aún la vegetación de los riscos, breñas y acantilados es quemada donde evidentemente ninguna utilidad práctica puede obtenerse y en cambio sí deja la roca desnuda a merced de los agentes aerógenos.

La fauna, por otra parte, está compuesta por algunas clases de ofidios, pequeños mamíferos (tinajos, cusumbes, guaguas, armadillos, erizos, zorros, venados, dantas, pericos ligeros y conejos), y por murciélagos.

Los osos, tigrillos y pumas se encuentran en las montañas que todavía no han sido colonizadas. Abundan los volátiles tales como torcazas y guacharacas. (Bernal, 1953: 283).

Como ya se sabe, el Macizo colombiano, reunión de tres cordilleras, determinó las direcciones tectónicas de la época terciaria; es el lugar de nacimiento de los tres ríos mayores de Colombia: Magdalena, Cauca y Caquetá.

Partiendo por el norte, con el Nevado del Huila y siguiendo hacia el oeste, en línea recta, bajándola perpendicularmente al Volcán Puracé, luego siguiendo esta recta hacia el este hasta la ciudad de La Plata (sobre el río La Plata) y luego hacia el norte hasta el Nevado del Huila, encontramos las siguientes formaciones geológicas, estudiadas parcialmente:
1. Mesozoico (Cretácico, Jurásico, Jurásico inferior o Liácico y Jura-Triásico).

2. Cenozoico.

a) Superior (Mioceno- Plioceno)

Terciario.

b) Inferior (Eoceno-Oligoceno), con rocas ígneas intrusivas post-jurásicas y más o menos paleozoica. (Banco: Cartograma 8,1959).

Puesto que Tierradentro está ubicada en la cuesta Oriental de la Cordillera Central, está más expuesta a las corrientes de aire provenientes de la región amazónica, lo cual origina un clima particularmente agradable, templado especialmente entre los $1.000 \mathrm{y}$ 1.500 metros de altitud.

La temperatura media se hace mayor en la hendidura de la llanura baja del Páez, en los llanos de Itaibe y naturalmente más pronunciada, más caliente, en las grandes llanuras de Carnicerías que se encuentran ya cerca de la reunión del Páez con el Magdalena. Así, pues, existen en Tierradentro subregiones que se escalonan entre los 1.000 y 3.500 metros de altura, de acuerdo con las cuales también cambia el carácter del paisaje. Por su situación protegida, se encuentran en regiones elevadas, productos que normalmente se dan en zonas mucho más bajas. Bürg menciona que en las cercanías de Belalcázar, se encuentran caña de azúcar junto a cereales; uvas junto a duraznos y manzanas, que generalmente se dan solo en clima frío.

Las características topográficas y climáticas permiten el cultivo de varias plantas tales como el maíz, fríjol, plátano, caña de azúcar, yuca, etc., en los climas templados, y en los fríos, papa, maíz, ullucos, habas, calabazas y repollos. Es una economía de subsistencia la de estos grupos, principalmente indígenas, de Tierradentro. La producción apenas si deja un ligero excedente para el comercio. El café y la producción de panela son renglones sustantivos en la economía de los colonos y también de numerosos grupos indígenas aculturados. La papa constituye otro renglón económico importante, especialmente para los Páez de la vertiente occidental de la cordillera, a través del Páramo de Moras (Bernal, op. cit.: 284), aunque también se comercia con ella en los días de mercado en Inzá y San Andrés. La ganadería es importante pero para los grupos colonos no indígenas.

La necesidad de tierras de cultivo ha llevado a los indígenas a colonizar partes selváticas montañosas pero, en algunos casos, encontramos cerca de San Andrés de Pisimbalá, en el Cerro de la Virgen, pequeñas granjas indígenas, en una de las cuales, uno de nosotros (Stanley Long) observó los siguientes productos agrícolas: 
Yuca, Manihot utilissima L.

Café, Coffea Arabiga L.

Plátano, Musa paradisiaca L.

Calabazo, Lagenaria vulgaris Serg.
Maiz, Zea maíz.

Arracacha, Arracacia xanthorrhiza Bancr.

Aguacate, Persea americana Mill.

Zapallo, Cucurbita maxima Duchesne (auyama).

Aji, Capsicum sp.

Lulo, Solanum quitoense (?)

Chachafruto, Erythrina edulis Triana.

Coca, Erythroxylon coca Lam.

Pina, Ananas comosus (L) Camargo.

Frijol, Phaseolus vulgaris L.

Guava, Psidium guajava.

Cebolia, Allium cepa L.

Cina, Saccharum officinarum $\mathrm{L}$.

Naranja, Citrus sinensis (L) Osbeck.

Sobre algunos de estos productos tenemos noticias desde la época de la conquista, i. e. Fray Pedro de Aguado (1906, tomo II 506) nos dice sobre los indígenas de Tierradentro, “... venían todos lo indios cargados de maíz, yucas, batatas y auyamas y otras raíces y legumbres que ellos acostumbran comer...".

\section{ETNOHISTORIA}

Los primeros informes sobre los habitantes aborígenes de Tierradentro comienzan solo a partir de la época de la conquista. Es una verdadera lástima que los primeros cronistas e historiadores del territorio Páez y sitios aledaños, sólo enfatizan y brindan abundantes detalles de las guerras que sostuvieron los españoles con los indígenas de esta zona. Pedro Cieza de León, Pascual de Andagoya, Fray Pedro de Aguado, Pedro Ordóñez de Ceballos, Juan de Castellanos y otros, son los escritores más conocidos del siglo xvi del Suroeste de Colombia.

Fueron todos participantes, testigos o por lo menos contemporáneos de la conquista del Alto Valle del río Magdalena, en cuyas tierras y montañas gobernaron los Páez y Pijaos, junto con otros grupos igualmente belicosos.

Excelentes noticias etnográficas fueron registradas por Manuel Rodríguez en el siglo xviI [hay que leerlo con cuidado pues contiene prejuicios de carácter religioso contra los indios] y Eugenio del Castillo y Orozco en el siglo xviII. Carlos Cuervo Márquez es bueno para el siglo pasado (muchos de sus datos son bastante es- quemáticos). Para el presente, constituyen una excelente fuente de información los trabajos de Jacinto Jijón y Caamaño, Jaime Arroyo y Segundo E. Bernal.

En esta sección se tratará de una manera muy sucinta, la etnohistoria de los grupos indígenas que tuvieron contacto con los españoles, desde el descubrimiento y conquista del territorio "Páez" hasta el presente, dejando a juicio del lector la consulta de recientes obras de etnología, especialmente las de Segundo E. Bernal. Debemos dejar constancia que las obras utilizadas como base, fueron las de Jijón y Caamaño y Segundo E. Bernal por encontrarse actualizadas, especialmente las del último mencionado autor.

El primer conquistador que divisó el Valle del Alto Magdalena desde las alturas del Macizo Colombiano, fue Sebastián de Belalcázar.

Nos cuenta Jaime Arroyo (1907) que a un hombre de las buenas dotes militares y administrativas de Belalcázar, no podía satisfacerle la situación de subalterno y menos el serlo de un caudillo como Pizarro, siempre egoísta y desleal. Así, pensó desde luego en sustraerse de esa dependencia y pasó del pensamiento al deseo desde que Pizarro, lejos de corresponder agradecido a sus buenos servicios y de conferirle, como debido premio, la gobernación del reino de Quito, le expresó que su hermano Gonzalo Pizarro ya le había solicitado aquel puesto.

Ocurriósele, pues, a Belalcázar expedicionar hacia el norte: pasar el límite de la Gobernación del Perú; descubrir la comarca que se extendía desde ella hasta el Darién; sujetarla al Rey de Castilla, y pretender de la Corte el derecho de gobernarla.

Un incidente feliz ocurrió a excitar estas disposiciones. El español Luis de Daza halló en Latacunga, caserío indígena cerca de Quito, a un indio extranjero que hablaba de su patria como de un país hermoso, fértil y sobre todo riquísimo en oro y esmeraldas; y refería, además, entre otras particularidades, que allí se ejecutaba anualmente un sacrificio singular y era que el señor principal de uno de sus pueblos, después de embetunarse el cuerpo y cubrirse todo con polvo de oro, se bañaba en el centro de una gran laguna y ofrecía a su (numen) dios tutelar, muchas alhajas del precioso metal, lanzándolas a las aguas entre el estruendo de la música y de las aclamaciones de la multitud.

A este respecto, Juan Rodríguez Freire o Fresle, nos relata lo siguiente:

$\ldots$ desnudaban al heredero en carnes vivas y lo untaban con una tierra pegajosa y lo espolvoreaban con oro en polvo y molido, de 
en la cual iba parado, y a los pies le ponían un gran montón de oro y esmeraldas para que of reciese a su dios. De esta ceremonia se tomo aquel nombre tan celebrado del Dorado, que tantas vidas ha costado, y haciendas. En el Pirú fue donde sonó primero este nombre Dorado; y fue el caso que habiendo ganado a Quito, donde Sebastián de Belalcázar andando en aquellas guerras o conquistas tocó con un indio de este reino de los de Bogotá, el cual le dijo que cuando querían en su tierra hacer su rey, lo llevaban a una laguna muy grande, $y$ de ála lo doraban todo, o le cubrian de oro, y con muchas fiestas lo haindio dorado!

(1963 : $54-55)$.

El indio cundinamarqués decía que solamente doce jornadas lo separaban de su tierra; Belalcázar ordenó que el capitán Pedro de Añasco con una partida de 60 hombres fuese a explorar y a inquirir noticias del Dorado en el país de Los Pastos (norte de Ecuador) del cual también antes había hablado el capitán Pedro de Tapia. No obtuvo dato alguno del Dorado, ni tampoco alhajas, ni minas de oro, pero sí de que más adelante, la cordillera se dividía en dos ramales que dejaba en medio de ellos una tierra limpia, fértil y abundante en oro, cuyos dueños eran Popayán (cacique de los Pubenses) y Calambás (señor de las tribus Paeces); el primero era dueño del valle de la ciudad de Popayán y las adyacentes serranías de Coconuco, y el segundo del territorio montuoso de la Cordillera Central que sigue al noroeste del distrito de Popayán.

Belalcázar acordó organizar mejor su empresa y como las leyes españolas vedaban acometer descubrimientos y conquistas sin expresa licencia de la autoridad superior, dio inmediatamente cuenta a Pizarro de lo ocurrido, pidiéndole autorizaciones para conquistar el territorio de Popayán como dependencia de la Gobernación del Perú o Nueva Castilla. Sin embargo Pizarro tardó en dar la autorización y sin que ésta llegara, encargó a Juan de Ampudia de un pequeño cuerpo de tropas, que ya estaba listo, para que, uniéndose en los Pastos con Añasco, siguiera lentamente explorando las comarcas del norte, mientras él podía marchar a unírseles. Salió Ampudia de Quito a mediados de 1535 con 60 infantes, 30 soldados de caballería y un número considerable de indios yanaconas (de servicio). La autorización de Pizarro llegó a Belalcázar el $1^{\circ}$ de noviembre de 1535 y no el $1^{\circ}$ de noviembre de 1537 como dice Julio Londoño (1967: 114).

En la tierra de los Pastos se juntaron el capitán Añasco y el otro capitán que se aunó a la expedición: Juan de Ampudia.

El indio cundinamarqués daba la ruta hacia el oriente, mas las penalidades de la Sierra y la crudeza de las lluvias obligaron a los españoles a virar hacia el noroeste. El cundinamarqués murió en el camino y con esto se desvanecieron las ilusiones de riqueza en aquellas regiones. Ampudia siguió hacia el norte, dejando a su paso huellas de sangre y desolación. Después de algún descanso, Ampudia siguió siempre hacia el norte, por la margen izquierda del río Cauca; penetró en el Valle de este río y fundó la Villa de Ampudia cerca de Jamundí. Uno de sus compañeros, Cieza de León, con varios hombres prosiguió su marcha, por en medio de multitudes indígenas, hasta Anserma.

Belalcázar alcanzó a Ampudia en la Villa fundada por éste (a cuatro o cinco leguas del actual pueblo de ese nombre: Ampudia). Como no le pareció el lugar muy apropiado para una fundación, la trasladó al Valle de Lile; siguió hasta Anserma, Quinchía y Supía, y a su regreso al Valle, mandó una expedición en busca de rutas hacia el mar Pacífico. El 25 de julio de 1536 funda la ciudad de Santiago de Cali. El 13 de enero de 1537 o en diciembre de 1536, funda la ciudad de Popayán para que fuese la sede del Gobierno.

La fecha de la fundación de la ciudad de Popayán ha sido un punto muy discutido. Martínez Delgado (1959:20-31), quien ha hecho un excelente caso de este problema, nos informa que según Castellanos y Fray Pedro Simón, Belalcázar tomó posesión del valle en forma definitiva el 24 de diciembre de 1536; el mismo Castellanos y Cieza de León señalan el año de 1536 como el de la fundación de la ciudad; el historiador Jaime Arroyo indica la fecha de 15 de agosto de 1537; Felipe Pérez anota el mes de diciembre de 1538; Flórez de Ocáriz, el año de 1536 sin precisar la fecha, etc., y a medida que avanza el tiempo y surgen más publicaciones, también surgen más errores. Julio Londoño (1967:115) anota el 15 de agosto de 1537.

Martínez Delgado (op. cit., p. 22) nos transcribe un documento, catalogado en el Archivo Central del Cauca bajo la signatura 8079 (Indepcia. J I $12 \mathrm{cv}$ ), que es una certificación del escribano Francisco de Vega Polanco y el cual nos ayuda en parte a resolver toda esta problemática. De éste solo damos la introducción:

En la muy noble y muy leal ciudad de Popayán cabeça de su provincia y obispado tierra firme de las yndias en beinte e queatro dias del mes de noviembre año del señor de mill e seiscientos e cinco ante el capitán Andres de la rroca, alcalde ordinario en esta ciudad y su término e jurisdicción Por el Rey nuestro señor y ante mi Franco. [Francisco] de vega Polanco escrivano de su magestad público y de cavildo desta ciudad Por su magestad la presento el contenido. clérigo presvítero hijo legítimo de diego de alvarado y catalina sánchez...

Diego de Alvarado pretende esclarecer los servicios y calida- 
des de sus padres abuelos y antepasados con lo cual presenta una serie de testigos sobre el particular y los cuales son interrogados.

De este interrogatorio más por la certificación del susodicho escribano y la cita del documento más antiguo en el libro del Cabildo, sale a relucir:

1. Que Ampudia fundó una villa en la Provincia de Popayán, a la que se le dio el mismo nombre de la que erigió después en la de Cali.

2. Que en la Villa de Ampudia está la primera etapa de la fundación de Popayán y se plantó por las instrucciones terminantes que se la habría aprobado.

3. Que Belalcázar en persona trasladó la Villa de Ampudia que se Popayán el 13 de Enero de 1537, y no en Diciembre de 1536, como dice Castellanos..

etc. Martínez Delgado (op. cit. p. 30) por otra parte informa que Enrique Otero D'Costa, en un interesante informe sobre la fundación de Popayán, presentado a la Academia Colombiana de Historia el 22 de agosto de 1937, entre otras cosas sostiene que debe continuarse aceptando el año de 1536 como el de dicha fundación, porque es el que predican los autores más antiguos y de reconocida fehaciencia, año que armoniza perfectamente con otras cronologías que giran en torno de él, lo que no ocurre con el de 1538 y además que lo más seguro que esa fundación ocurriera por el mes de diciembre del citado y aceptado año, y lo más posible que se efectuara el día 24, o sea la víspera de la Pascua de Navidad. Está fuera de nuestro alcance poder dar la última palabra sobre el particular, pero no podemos de dejar de señalar la importancia del documento transcrito por Martínez Delgado, el cual debe correlacionarse y compararse con otros que posiblemente existan en el Archivo General del Cauca o en Bogotá pero, por otra parte, tampoco podemos dejar de aceptar la fecha de la fundación de Popayán (13 de enero de 1537) que aparece en el margen de un documento hallado en el libro más antiguo del Cabildo de dicha ciudad del cual Francisco de Vega Polanco hace mención en su certificación.

Con el pensamiento fijo en el Dorado, Belalcázar exploró los nacimientos del río Cauca, subió hasta los páramos del Buey, páramo de las Papas; observó la vastísima hoya del río Magdalena y decidió que aquella era la ruta que debía seguir en busca del Darién y del Dorado.

Sobre este respecto tenemos algún informe dado por Jacinto Jijón y Caamaño:

Al tratar de Tatabe advierte Cieza; estiéndense estas naciones hasta la mar del Sur la vía del poniente. Por el Oriente confinan con el gran río del Darién. Todas estas comarcas son montañosas muy y muy temerosas. Cerca de aquí dicen que está aquella grandeza e riqueza del Dabaybe tan mentada en la Tierra Firme.

$(1938:$ II * 155)

Belalcázar halagó a sus coterráneos con la esperanza del Dorado. Este era el sebo que ponían los conquistadores españoles; con este halago atraía a los fines que él perseguía, que eran: colonizar, fundar y asegurar la tierra. Belalcázar hablaba del Dorado pero no se afanaba por encontrarlo y cuando regresó de España con el título de Adelantado y Gobernador Perpetuo de Popayán, no habló más de él.

Al partir para España, dejó como Gobernador de la ciudad al capitán Francisco García de Tovar y éste, con aproximadamente 100 hombres de a caballo y 200 de a pie, abrió la marcha hacia las cabeceras del río Cauca.

Los oficiales más prestigiosos que llevaba eran Pedro de Añasco, Juan de Ampudia y Cabrera. Siguió el curso del río hasta llegar a la laguna de su nacimiento al norte del gran nudo llamado hoy Almaguer. Nacen en esta zona cinco grandes ríos que bañan el territorio colombiano: San Jorge (afluente del Patía), Putumayo, Cauca, Caquetá y Magdalena.

La expedición siguió hacia los grandes valles del Magdalena; en esa larga y penosa expedición de cuatro meses, los españoles no encontraron resistencia alguna por parte de los Páez, quienes se encontraban a la sazón ocupados en guerrear con otras tribus indigenas.

Antes de partir para España con Quesada y Federman, dispuso Belalcázar que Pedro de Añasco fundara Timaná y que el capitán Juan Cabrera fundase la ciudad de Neiva en el Valle del Magdalena. La fundación se efectuó en el sitio que se conoce con el nombre de Tapias, cerca de Campo Alegre y al río más próximo se le llamó Neiva. Fundada en 1539, fue destruída por los Pijaos en 1569. En 1612 fue reedificada por los Padres Jesuítas con el nombre de Villavieja.

Los grupos indígenas con los cuales se encontraron Belalcázar y sus capitanes eran en su mayoría Páez. Los Páez ocupaban en la Cordillera Central, la parte comprendida entre las cumbres del Nevado del Huila y las del Puracé y se extendían a uno y otro lado de la Cordillera, pero su asiento principal estaba en la hoya hidrográfica del río Páez, una de las más fragosas regiones de los Andes Colombianos. Desde los tiempos de la conquista se la llamó Tierradentro. Nombre significativo, alusivo quizás a su difícil acceso, a su 
suelo áspero, desigual, de altísimos cerros, surcados en todas direcciones de ríos torrenciales, de cauces profundos y cubierta de selvas.

El Padre Simón refiere que en las provincias de Neiva, los españoles encontraron un sitio que llamaron Carnicerías, con unos grandes bohíos donde se vendía carne humana de los prisioneros que cogían en las guerras, con tanta abundancia que la gente concurría allí a comprarla, principalmente los Pijaos, ya que los Páez no eran caníbales; este mismo hecho lo anota Carlos Cuervo Márquez (1920, Vol. II, p. 153).

Durante la ausencia de Belalcázar, Pedro de Añasco fue a Popayán y se hizo reconocer como teniente gobernador de la ciudad por él fundada: Timaná. Obtuvo la facultad de repartir indios en encomiendas entre los principales vecinos y regresó llevando ganado, herramientas y semillas. Inmediatamente practicó los repartimientos con desagrado de los naturales. No obstante, los caciques y demás jefes indígenas no mostraron al pronto su descontento, antes bien y obedeciendo las órdenes de Añasco, concurrieron a Timaná en determinado día a oír de su boca las obligaciones a que quedaban sujetos.

Un mozo principal, hijo de la Gaitana, señora de las más potentes y que por toda la tierra extendía su poder, que mandaba a muchas gentes, no quiso acudir como vasallo de Añasco. Añasco procuró castigarlo como ejemplo para los demás. Envió mensajeros a prenderlo y lo sentenció a morir hecho brasas y cenizas. No valieron los ruegos ni el llanto de su madre.

La madre, enloquecida de furia por tan inútil crueldad, juró vengar al hijo, logrando interesar en la demanda a todas las tribus circunvecinas, incluso la que comandaba Pigoanza, el padre del mancebo mimado de Añasco.

(Jijón y Caamaño, $1938:$ II : 43-44).

Jijón y Caamaño (op. cit., p. 44) continúa con su informe sobre Añasco:

En este tiempo, el capitán Pedro de Añasco habíase salido de Timaná por venir a Popayán y mercar caballos y anduvo hasta llegar a los Yalcones... Y como los naturales de aquellas regiones son muchos y determinados y que pelean con lanzas de a treinta palmos y otras armas muy malas, juntáronse los más principales de ellos, y trataron de rebelarse contra los españoles, y no solamente negarles la obediencia, mas procurar de matar al Capitán y a los mercaderes que venían de Popayán.

Pedro de Añasco se asentó en el Valle de Ayunga (según Arroyo, 1907: 156 es Aquisga). El hijo de Pigoanza, quien estaba al servicio de Añasco, supo por ciertas indias de la liga que habían hecho los Yalcones, Páez y otros indios comarcanos, además, el re- gaio que unos inuiuus le hicieron a Añasco era signo de mal presagio (un cachorro de tigre?), le advirtió inmediatamente sobre el inminente peligro que corría pero éste no le hizo caso. El ataque pronosticado se hizo efectivo y Añasco fue hecho prisionero y entregado a la Gaitana;

quien le hizo sacar los ojos y pasar una cuerda por la mandíbula inferior, con la que se le conducía como trofeo de caserio en caserío. Cuando ya los dolores y la gangrena iban dando muerte a Añasco, le cortaron las extremidades y los órganos viriles.

(Jijón y Caamaño, op. cit., p. 46-47).

En 1540, los Yalcones y Páez asesinaron casi simultáneamente a Añasco y a Osorio y destruyeron a Timaná. Este último acompañaba el convoy del mercader Pedro López, que iba de Popayán a Bogotá.

Juan de Ampudia, en cuanto supo de los fatales acontecimientos, se encaminó a castigar a los indios. La lucha fue porfiada y desastrosa. Todos los elementos estaban contra los españoles. Los hombres de Ampudia estuvieron impedidos para usar sus espadas con entera libertad, ni los perros, arma poderosa y decisiva en mil encuentros, pudieron hacer ahora carnicería en la bárbara multitud. Ampudia cayó herido de muerte, después de un largo e incesante batallar.

Haciendo prodigios de valor, García de Tovar recogió, en orden y a cierta distancia, la reducida tropa, armó tiendas, prendió hogueras, amarró a los perros para que con los aullidos infundieran algún respeto y protegido por las sombras de la noche, huyó a Popayán en mayo de 1540. Los indios continuaron sus ataques y sin duda alguna hubieran destruído a Popayán si no hubiese sido por la oportuna intervención de Pascual de Andagoya, quien el 10 de mayo de 1540, al saber en Cali la muerte de Añasco y que los indios tenían cercada la Villa de Timaná fundada por éste el 18 de diciembre de 1538 (?), se dio prisa en ir a resistirles la entrada a Popayán. Llegado a Popayán, envió luego, por un camino secreto, un capitán con cincuenta arcabuceros y ballesteros a socorrer a Timaná.

Andagoya ejerció durante algún tiempo la gobernación de Popayán; fue el primero que trabajó entre los españoles de occidente, pro-evangelizar y catequizar a los indios.

Belalcázar, al regresar de España (1540), supo la muerte desgraciada que habían corrido sus capitanes Añasco y Ampudia y el peligro en que se había hallado el capitán García de Tovar y la misma ciudad de Popayán. 
...en el Verano de 1543 [probablemente 1541] acordó Dn. Sebastián por su propia persona e las de algunos principales de la Gobernación e vecinos della e otra gente de guerra que en ella avia, poner como dicen faldas en cinta e entrar en las dichas provincias e hacerlas pacíficas.

(Jijón y Caamaño, op. cit., p. 226).

Los indios después de rudo batallar habían arrojado de sus tierras a los intrusos y estaban resueltos a no dejarlos entrar en lo sucesivo.

Obstruyeron los caminos que conducían de Popayán hacia la cordillera, habían talado los campos y amenazaban de continuo a las ciudades españolas. Con gran actividad y prudencia organizó Belalcázar la expedición para ir, él mismo, a pacificar o aniquilar si fuese necesario a los Páez. Las noticias del ataque fueron a dar a los oídos de éstos, quienes se aprestaron a la defensa.

Desde el principio experimentó dura resistencia. Todo ayudaba a los Páez; altísimos cerros para observar al invasor, montañas que eran verdaderos arsenales de piedras, desfiladeros, sendas que bordeaban ríos peligrosos; toda la comarca parecía enemiga a los españoles y se empeñaba en cerrarles el paso. A pesar de su posición ventajosa, los españoles derrotaron a los indios Páez parcialmente. El Adelantado se dio cuenta de que fortificado en las alturas del Peñón de Tálaga se encontraba el grueso del ejército enemigo y se dispuso a desalojarlo. Los capitanes Martín Nieto y García Tovar fueron escogidos para esa misión.

El capitán Nieto con cincuenta peones debía tomar el sendero de la derecha, Tovar con otros tantos, el de la izquierda, y al amanecer habrían de tener ambos coronada la altura y comenzado el combate, mientras Belalcázar con el resto de la gente, atendería a las necesidades que las circunstancias indicaran.

El combate que empezó en la vega del norte del Peñón, se extendió al sur. Belalcázar manejó la caballería en un terreno cubierto de zanjones, las laderas difíciles que impedían el manejo de los caballos, los obligaban a dar rodeos, a avanzar y retroceder. En tan difícil situación, la retirada le pareció el único recurso. Disminuída, maltratada y moralmente afligida, regresó la expedición a Cali. Se ignora a punto fijo la fecha en que los derrotados de Tálaga regresaron a Cali, pero sí se sabe que el 7 de septiembre de 1541, se hallaba Belalcázar en Popayán.

Con respecto a la derrota de Belalcázar, dice Jijón y Caamaño:

No pudo don Sebastián coronar esta expedición punitiva, estaba casi al remate de ella, cuando otros requerimientos de su gobierno le obligaron a dejar la empresa en manos de su Teniente General Juan de Cabrera, y volverse hacia el norte, quedando su hijo Francisco de teniente de Popayán.

(Op. cit. p. 241).

En muchas de las obras consultadas, se informa de la derrota de Belalcázar en 1543, en el Peñón de Tálaga, principalmente Cuervo Márquez y Jijón y Caamaño. Si se acepta el año de 1543 como la fecha de esta derrota, entonces Jijón y Caamaño tienen razón. Hay que tener en cuenta el hecho de que Belalcázar regresó de España en 1540 y es poco probable que esperara 3 años para iniciar su campaña en 1543 contra los Páez, lo más probable es que su campaña comenzó inmediatamente después de su regreso de España, con lo cual nuestra fecha de 1541 sería la correcta.

En 1562, el capitán Domingo Lozano entró en el territorio Páez con el deseo de establecerse y sojuzgar a los indios. Los indios no cooperaban. La única condición bajo la cual los nativos harían la paz, sería si los españoles abandonaban el territorio. Nueve años más tarde, los Páez aliados con los Pijaos, asesinaron al capitán Lozano y destruyeron el pueblo por él fundado: San Vicente de los Páez. Cuervo Márquez (1920: 161 - 162) dice que "en julio de 1563, los paeces, que hasta el día anterior se habían mostrado como amigos, se reunieron y atacaron a Lozano".

Uno de los caciques Páez, Calambás, a quien una familia en la Plata no quiso devolverle una hija que les había dejado en custodia mientras se celebraba la fiesta del Santo Patrono, se volvió a sus montes y ofuscado por la ira, reunió a los combatientes de la nación Páez y con sus aliados, los Guanacas, Yalcones, Andaquíes y Pijaos, marchó hacia La Plata.

Fue una masacre completa, no se respetó ni mujeres, ni niños, todos perecieron el 17 de junio de 1577 (1571 según Cuervo Márquez, 1920, vol. II: 165 y 1573 según Friede, 1953: 81).

En 1579, don Sancho Espinar, Gobernador de Popayán entró a la zona para castigar a los Páez y Pijaos. Los indios se retiraron tácticamente y el Gobernador, creyéndolos conquistados, regresó a Popayán. Nuevamente, los Páez aliados con los Pijaos, destruyeron el pueblo de Caloto.

Los Páez y los Pijaos odiaban todo cuanto pertenecía a sus enemigos: los españoles. Recibían de ellos asesinatos, incendios y destrucción y les pagaban en la misma forma, con asesinatos, incendios y destrucción. 
La subyugación de los Páez vino con el aniquilamiento (?) de los Pijaos por el Presidente de la Real Audiencia, Don Juan de Borja, en el Valle de Chaparral.

Una vez que don Juan de Borja se enteró bien del Gobierno y puso en orden todos los asuntos de su administración, dedicóse a organizar la guerra por la paz. Despachó capitanes para los valles del Magdalena, se buscaron los contrafuertes y sinuosidades de la cordillera. Salió de Santafé de Bogotá el 27 de enero de 1607 hacia el territorio Pijao, ya que éste era el grupo más belicoso. El Presidente Borja dispuso su campamento en el Valle de Amoyá, en el lugar que hoy ocupa Chaparral. Mientras recorría los campos para disponer el ataque supo que los enemigos saqueaban e incendiaban a Ibagué. "El último asalto Pijao a una ciudad [Ibagué] se llevó a cabo en la noche del 18 de julio de 1606 . Simón difiere en esta fecha en un día, pero creemos que se debe al hecho de que fuera medianoche, con lo que sería todavía 18 para Borja y 19 para el cronista". (Lucena Salmoral, 1965: II : 145).

El enemigo era poderoso: Pijaos, Páez y aliados, veteranos en la lucha y conocedores minuciosos del terreno. Una circunstancia favoreció de manera especial al Presidente Borja. Los Pijaos tenían dos grandes jefes rivales que se disputaban la supremacía. El cacique Calarcá, que moraba en la parte occidental de la cordillera y el cacique Coyaima, dueño de la región oriental. Tuvo el español habilidad para ganarse la simpatía y amistad de Coyaima y hasta logró hacerlo cristiano con el nombre de Baltasar. Puso en sus manos la lanza de Castilla, lo adiestró en su manejo, le dio el encargo de enfrentarse, siempre bajo su dirección, al odiado rival, el cacique de Calarcá. Este cruzó la cordillera con su ejército de Pijaos y Paeces; los españoles, Coyaimas y Natagaimas, después de muchos movimientos de estrategia, llevaron al enemigo al Valle de Amoyá (Chaparral), allí se desarrolló el combate que quebró definitivamente el poderío de los Pijaos y Paeces antiespañoles, enfrentándose los dos rivales.

Los pocos Pijaos que quedaron, asociados con los Páez, todavía ofrecieron resistencia en el Valle de Mana o Pijao en Itaibe (territorio Páez) en 1608. Aunque los indios no fueron derrotados completamente, decidieron retirarse. Borja, en lugar de atacarlos, resolvió enviar misioneros a catequizarlos.

Sin embargo, en 1656, se notó que en el cacicazgo de Togoima hubo un atentado contra el pueblo de Neiva. El capitán Fernando Villarroel contrarrestó este ataque, hizo prisioneros y los jefes fue$-32$ ron obligados a jurar que en el futuro no perpetrarían ningún ataque más (González, David, Los Paeces, Ms. c. f. Bernal, 1956 : 21).

En la segunda mitad del siglo xvII y en los siglos XviII y XIX, los Páez permanecieron relativamente en calma. Puesto que el territorio no es muy rico en oro, y sí, muy quebrado y de difícil acceso por un lado y por otro la carretera del Quindío que, por ese entonces estaba recién abierta, disminuyeron la importancia de la región quedando así los Páez en aislamiento. Sólo los misioneros y colectores de tributos reales entraban. Sin embargo, a mediados del siglo pasado, los Páez ayudaron a la causa del General Mosquera en su rebelión contra el Gobierno constitucional. Ganó la batalla de Segovia que abría las puertas del Valle del Magdalena y como resultado, aquellas de la capital de la República.

En el presente siglo, en 1912, Quintín Lame condujo un ataque contra el pueblo de 'blancos' de Inzá. En 1932, otro jefe Páez, Pío Collo, levantó a los indios contra la Prefectura Apostólica de Belalcázar. Finalmente, en 1950, los políticos de Belalcázar, entre ellos Pío Collo, levantaron a los indios contra el Alcalde de esa ciudad.

La agresividad de los Páez, ahora como en la época de la conquista, surge cada vez que el 'blanco' trata de robarles sus tierras.

Pedro Cieza de León, calificado por algunos como el mejor de los etnólogos españoles para Sur América, dejó una corta pero precisa descripción de los Páez y su territorio. Este cronista dice:

A la parte oriental está asimismo la muy porfiada provincia de los Páez, que tanto daño en los españoles han hecho, la cual terná seis o siete mil indios de guerra. Son valientes, de muy grandes fuerzas, diestros en el pelear, de buenos cuerpos y muy limpios; tienen sus capitanes y superiores, a quienes obedecen; están poblados en grandes y muy ásperas sierras; en los valles que hacen tienen sus asientos, y por ellos corren muchos ríos y arroyos, en los cuales se cree que habrá buenas minas. Tienen para pelear lanzas gruesas de palma negra, tan largas que son de a veinte y cinco palmos y más cada una tiempos.

Han muerto tantos y tan esforzados y valientes españoles, así como capitanes como soldados, que pone muy gran lástima y no poco
espanto ver que estos indios, siendo tan pocos, hayan hecho tanto mal...

(1962 : 109).

Evidentemente, en este párrafo no aparece el 'canibalismo', el cual, en forma general, se menciona en varias obras cuando se dice que el cadáver de Juan de Ampudia fue arrebatado a los indios para evitar que éstos se lo comiesen.

Cieza de León (op. cit.) nos menciona que los indios atacaban en la madrugada, lo cual también dice Castellanos, quien además, nos cuenta que los indios desollaban los caballos y jinetes y los re- 
llenaban con cenizas, quitando antes la carne para hacer sopa y utilizando el cráneo como copa para beber.

Más importante por la abundancia de datos etnográficos que los cronistas antes discutidos, es Fray Pedro de Aguado. Este sacerdote estuvo en Popayán cuando el Capitán Lozano estaba ocupado en sojuzgar a los Páez.

Su crónica aparece, en realidad, como si fuese el diario del capitán Lozano. La meticulosidad con que describe el territorio que atravesó el desafortunado capitán es sorprendente. Por la descripción, podemos ver que el itinerario fue el que sigue por las actuales parcialidades de Calderas, Lame, Suin, Chinas, Avirama, Togoima, Belalcázar, Ricaurte, Toes y Huila, todas en territorio Páez. Pero las provincias de Vitoncó, Mosoco y San José, por las cuales entró el capitán, no figuran en la descripción, todas pertenecientes al Alto Valle del río Moras.

Aguado niega categóricamente que los Páez comían carne humana pero sí afirma que era una costumbre la de tomar las cabezas humanas como trofeos. Dice:

muertos algunos indios, los cuales con gran presteza los amigos (la gente de Esmisa) procuraban tomar parte quitarles las cabezas y desollarles los rostros y aforrarlos en ciertas calabazas, donde los conservan y tienen memoria de su victoria. También se cargaban de brazos y piernas y otros pedazos de indios muertos para que comiesen algunos Pejaos que con ellos venían, porque los Esmisas y Anabeimas y los demás indios Páez no comen car humas co y solamente de los indios muertos en la ruerra toman los rostros; como he dicho.

(Aguado: 352, c. f. Bernal, 1956: 26).

Importante entre los cronistas del siglo xvir, es el jesuíta Manuel Rodríguez, quien de acuerdo con sus narraciones, anduvo por los valles de Buga (Valle del Cauca) y Neiva (Valle del Magdalena). Aunque este sacerdote estaba más interesado en la Historia de las misiones jesuítas, dejó algunos datos etnográficos con respecto a los Páez; hace referencia a la destrucción del pueblo de Caloto y nota la tradición que tienen sobre la destrucción de las campanas de la iglesia y la obligación que tenían de ir dos veces al año a Popayán a trabajar en las haciendas de sus amos.

Los jesuítas permanecieron 27 años entre los Páez tratando de catequizarlos; como sus intentos no tuvieron resultados positivos, abandonaron la empresa. La amargura de este fracaso se refleja en el Padre Rodríguez, cuando dice:

La gente es de la más bárbara, o incapaz que se ha descubierto en la América, de que con fundamento se pudo dudar, si eran racionales: su mas conocida inclinación, es al ocio, y á la embriaguez, y esta les obliga á juntarse á vezes unas familias con otras acabandose de ordinario con riñas el regozijo de sus bebidas, y siguiendose della otros pecados...

(1684: 73)

Entre los aspectos más notables observados por los cronistas de los siglos XVI y XVII es el patrón de establecimiento de las familias Páez. Las familias vivían dispersas por la región, a veces separadas unas de otras por varias millas. Naturalmente, cada familia era una unidad reproductiva, educativa, económica, social y religiosa. Esta familia, de acuerdo con los cronistas, abandonaba su casa si moría una persona o si una mujer daba a luz dentro de ella.

Las casas, ó choças, que tienen en aquellas cordilleras, á una, y otra vanda del Río de Paez, distan leguas enteras, unas de otras, y siempre, que pare la muger, ó que muere alguno de su familia, desamparan la casa, dexando en ella al difunto con cantidad de bastimento, y de la chicha, brevage, que beben, $y$ á las casas donde parió la muger, las dexan con las inmundicias de el parto, y acabadas de nace las criaturas, á buscar nuevo parage para su habitación..

(Rodríguez, 1684: 26).

Los miembros de la familia masticaban y mastican coca, les gustaba el ocio y las fiestas con otras familias, donde una vez borrachos, peleaban y cometían otros pecados tales como relaciones sexuales.

A pesar de que los cacicazgos Páez se unieron para luchar contra los españoles, no alcanzaron el estado de organización sociocultural. Así pues, los Páez, al tiempo de la conquista estaban organizados y funcionaron a nivel de cacicazgo, el cual corresponde aproximadamente a un nivel de comunidad en el cual la familia tiene un papel preponderante debido a la ausencia de aldeas.

$* * *$

El doctor Reichel-Dolmatoff, excelente conocedor de las fuentes históricas de Colombia, ha hecho las siguientes localizaciones de las tribus del siglo Xvi sobre el río Magdalena:

\section{PANTAGORA}

En la ribera izquierda del río Magdalena, desde el río Guarinó al sur hasta el río San Bartolomé al norte. Esta zona incluye la hoya del río Porce y las cabeceras del río Nechí, hasta el río Siguaná al norte. El límite oeste va hasta el río Cauca; viene por la falda occidental de la Cordillera Central; en el río Cauca desde la hoya del río Timaná (el cual desemboca en el San Juan) hasta Cenufana. 
Inclúyense los indios del Valle de Aburrá, la tribu de Guamoco (Serranía de San Lucas), los Yamecí en la ribera derecha del Cauca, la tribu Nutabe y Tahamí. Los Yamecí sobre el río Porce y los Guamoco un poco al NE de la actual ciudad de Zaragoza.

\section{LOS PANCHES}

Al sur de los Pantágoras, pero en ambas riberas del río Magdalena, en la ribera occidental, por Honda, el límite norte es el río Gualí y en la ribera oriental, es el río Negro. El límite sur es el río Coello y el río Fusagasugá. Por el este colindan con el territorio Chibcha y por el oeste con el filo de la Cordillera Central.

\section{LOS PIJAOS}

Están al sur de los Panches, no solamente en la hoya del río Magdalena, sino penetran hasta el río Cauca. Se incluyen:

1. Los indios del Valle de Miraflores en la hoya del río Luisa por los lados de Chaparral.

2. Tribu de los Otaimas, sobre el río Otaima (hoya del río Otaima).

3. Los Tuamo, en la hoya del río Cucuana, afluente de la ribera izquierda del río Saldaña.

4. Los Lucira, al lado de los Tuamos.

5. Los Anatoima en las cabeceras del río Tetuana.

6. En la Mesa de Chaparral, estaban los grupos:

Amoyá,
Ambeima,
Irico,
Peuni,
Maito.

Los Amoyá, más o menos sobre el río Amoyá. Los Ambeima sobre el río Amoyá y en su afluente el río Ambeima. Los Irico en la hoya del río Irico. Los Peuni hacia las cabeceras del río Tetuana. El río Irico es afluente derecho del río Amoyá.

7. Los indios de valle de la Palma en la Quebrada Palma, afluente del río Saldaña (arriba del Amoyá). Los Totumos en la Quebrada Totumo, afluente derecho del bajo río Amoyá.

Otros grupos o tribus que pertenecían a los Pijaos: 1. Paloma, en las cabeceras del río Amoyá, entre Ortega y Cha-
parral.

2. Tonuro, vecinos de los Paloma en la misma región.

3. Grupos Hamay y Zearco, en el río de las Nieves, afluente derecho del río Amoyá.

4. Cutiba, en un valle que desemboca en el río Aipre y en la cordillera entre el río Aipre y el río Saldaña.

5. Natagaima, Organos y Pana, en la misma cordillera entre el río Aipre y el río Saldaña.

6. Ombecho, en la hoya del río Saldaña.

7. Coyaima, en ambas riberas del Magdalena, desde la Mesa de Chaparral por la hoya del río Ortega, luego por todo el Valle la Tristeza).
la Timaná (es todo lo que se llamaba el Valle de

8. Poima y Yaporogue, en ambas riberas del Magdalena, entre el río Coello y el río Bache, cerca de Neiva.

9. Sutagao, en las hoyas de los ríos de Pasca y Sumapaz. Sus tribus eran: Sumapaz, Doa y Cunday.

\section{MACIZO COLOMBIANO}

1. Guambia, al este de Cali y Jamundí, en las faldas de la cordillera. Al norte de los Buga.

2. Páez, al sur de los Guambias y la parte norte del territorio Páez. Esste territorio estaba y está también ocupado por los indios Coconucos.

3. Yalcón, entre los Páez y las cabeceras del Magdalena. Algunos de estos grupos ocupaban las cabeceras y van hacia el este y limitan con los Pijaos.

4. Andaquí, en la región de San Agustín.

5. Guanaca, un pequeño grupo dentro del territorio Yalcón en la parte norte.

6. Timaná, al este de los Andaquí y al sur de los Yalcón, en las cabeceras orientales del río Magdalena.

De los grupos antes mencionados, nos referiremos específicamente a dos: Páez y Pijaos.

Los Páez en la actualidad viven en parcialidades. Una parcialidad es una unidad política, regulada por las Leyes de Colombia, pero esencialmente es una unidad social, una comunidad. Cada uno 
de los comunitarios es consciente de la extensión territorial, conoce los límites exactos de la parcialidad y los defiende cuando ellos son vulnerados; además, cada parcialidad tiene sus propias fiestas religiosas qué celebrar y su vida social qué vivir. La comunidad suministra tierra a sus miembros y protege la vida de los mismos; cada uno de ellos tiene derechos qué gozar y deberes qué cumplir Esto no implica que la comunidad sea necesariamente una unidad de parentesco, pero este hecho, junto con la residencia común, la amistad, la cooperación económica y el gobierno común, crean lazos de cohesión que definen la comunidad. En cada comunidad existen sentimientos de in-group completamente definidos. (Bernal, 1961: 22 - 34)

Las parcialidades Páez que actualmente existen dentro del teritorio de Tierradentro son: catorce (14) en el Municipio de Páez: Ricaurte, Cuetando, Araújo, Belalcázar, Avirama, Chinas, Suin, Tosé, Huila, Toez y Tálaga, y siete (7) en el Municipio de Inzá: Topa, Turminá, Guanacas, Yaquivá, San Andrés, Santa Rosa y Calderas.

Con respecto a los $\mathrm{Pijaos}$, éstos fueron desde hace mucho tiempo considerados como extintos, hasta que a mediados del año de 1943, el Ministerio de Educación Nacional de Colombia encargó a los doctores Reichel la investigación sobre la existencia de un núcleo indígena Pijao en el Departamento del Tolima. Soprendentemente Municipios ado vericultura, han conservado muchas zados, vestidos y dedicados a la agricultura, han conservado muchas de las características de su antigua cultura matericia y Gerardo, 1944: 507).

(Reichel-Dolmatoff, Alicia y Gerardo, 1944:

Los antes mencionados autores localizan

\section{MUNICIPIO DE ORTEGA}

El primer grupo comprende la parte montañosa de la Cordillera de Calarma, las cabeceras de los ríos Loaní y Toy, es decir, la región donde los indígenas viven más aislados y dispersos. El segundo grupo comprende la planicie entre la Cordillera de Calarma y los cerros que la limitan hacia el río Saldaña, donde los indígenas son agricultore en pequeña escala, y el tercer grupo comprende la region ribereña
del río Saldaña con sus pescadores.

(1944: $509-510)$

\section{MUNICIPIO DE COYAIMA}

El primer grupo corresponde a la región ribereña del río Sal-
Castilla. El segundo grupo abarca toda la extensión de la fracción política de Chenche situada en los llanos, en ambas riberas del río del mismo noure donde viven indión eńo de pequaima escala, comunicandoser de Meche hacia el Municipio de Natagaima y el río Magdalena.

(1944: 513).

MUNICIPIO DE NATAGAIMA

El primer grupo se encuentra en el norte del Municipio, limitando con el de Coyaima y comprendiendo la población de Natagaima. El segundo grupo abarca las fracciones politicas en la ribera izquierda del río Magdalena, y el tercero, las de la ribera derecha.

(1944: 515).

En vista de esto, tal idea del aniquilamiento y desaparición total de los Pijaos está obsoleta, y muy por el contrario, debería estudiarse este núcleo sobreviviente, aunque existe la posibilidad de que estén más aculturados, ya que han pasado 24 años desde que los doctores Reichel los estudiaron (básicamente los grupos sanguíneos). Por otro lado, en el Archivo General de Indias y en otros, existen documentos sobre estos indígenas, principalmente un informe de 43 folios, existentes en la Sección 196 del Patronato Real del Archivo General de Indias, en el cual el Presidente, Gobernador y Capitán General del Nuevo Reino de Granada, don Juan de Borja, da minuciosa noticia sobre la guerra sostenida contra los Pixao hasta el 20 de junio de 1608 , los cuales han sido estudiados por Lucena Salmoral (1962 y 1965).

\section{CONDICIONES GENERALES DE INVESTIGACION}

El proyecto arqueológico de Tierradentro se llevó a cabo en San Andrés de Pisimbalá, El Tablón, El Volador, El Marne, El Rodeo y Segovia. En estos lugares obtuvimos material cultural relativamente abundante tanto de las excavaciones como de las recolecciones superficiales que hicimos en varios sitios de esta región.

Nuestras condiciones de investigación, en general, fueron buenas y fáciles, si las comparamos con otras excavaciones hechas en Cupica, Colombia, o en la región selvática del Brasil; naturalmente tenemos que anotar que el medio ambiente en las dos zonas antes mencionadas es muy distinto al de Tierradentro, pero tienen una cosa en común: la cantidad de lluvia, que consideramos es uno de los peores elementos meteorológicos para los arqueólogos. 
Contamos con una época de constantes lluvias, muchas veces torrenciales, las cuales dificultaban el transporte y trabajo pero en ninguna forma fue un obstáculo insalvable, ya que nos hicimos de una tolda la cual nos permitió trabajar normalmente aún cuando llovía.

Los sitios excavados quedaban algo retirados de nuestras viviendas y por lo tanto cada día de trabajo implicaba una movilización y acarreo, tanto del personal como del equipo (picas, palas, palustres, mira, teodolito, bolsas, etc.), a pie y/o a caballo, según el sitio de excavación, así como la de nuestros alimentos, ya que algunas veces por la distancia nos vimos obligados a tomarlos en el lugar de trabajo y en esta forma ahorrámos tiempo. Nuestra jornada de trabajo en el campo oscilaba entre 8 y 10 horas diarias y a veces 12.

Los pozos se excavaron de acuerdo con las necesidades de la investigación y con las posibilidades del o los sitios. El material cultural, una vez extraído del pozo, fue empacado y rotulado inmediatamente. A veces las bolsas con su contenido fueron dejadas depositadas en alguna casa cercana, otras veces las acarreábamos inmediatamente, a caballo o en mula, hasta nuestra estación en el hotel del Parque Arqueológico de Tierradentro.

En cada bolsa de lienzo (tela), se escribió con bolígrafo (ya que su tinta es más resistente a la humedad) en la parte exterior, el nombre del sitio, el número del pozo y el nivel excavado. Estos mismos datos una vez que fueron transcritos en una tarjeta de cartón, se incluyeron en la respectiva bolsa, para mayor seguridad y evitar errores. El material cultural fue lavado y secado en nuestra estación en Tierradentro. Una vez que lavamos, secamos y reempacamos el material, a cada bolsa, la cual ya había sido amarrada con hilo de cáñamo y rotulada nuevamente (la mayoría de la cerámica fue reempacada en bolsas nuevas, las viejas e inservibles se quemaron para evitar confusión) se le adicionó una placa de cobre amarrada con alambre. A la vez se elaboró un catálogo anotando el número de la ficha de cobre, el sitio de la excavación, pozo y nivel a que correspondía el material de cada bolsa; el catálogo se copió en dos libretas de campo para tener así un duplicado en caso de algún accidente.

No tuvimos muchos problemas con la labor fotográfica y topográfica, pues a pesar de que llovía, hubo momentos de sol. Climáticamente fue una época muy inestable.

No descartamos ningún material cultural, excepto aquellos que se desprendían de las paredes de los pozos cuando se limpiaban y de los cuales no podíamos precisar su nivel de origen. Por lo demás, todo el material pudo ser transportado en camión, desde el Parque Arqueológico de Tierradentro hasta el Departamento de Antropología de la Universidad de los Andes, Bogotá.

A mediados de agosto de 1968 se terminaron de analizar los materiales cerámicos, los cuales fueron remitidos al Museo Nacional en Bogotá, especialmente las urnas funerarias y vasijas encontradas en las tumbas 1 y 2 de nuestra excavación y que corresponden a los números $\mathrm{X}$ y 7 en el mapa de curvas de menterio de Segovia; también se envió una muestra de la tipología cerámica establecida por nosotros.

Antes de nuestras investigaciones, del 12 de junio al 15 de agosto de 1967, varias personas y expediciones habían trabajado y visitado diversos sitios, dentro y cerca de la zona arqueológica de Tierradentro. Entre ellos tenemos a :

\section{Fray Juan de Santa Gertrudis:}

Este sacerdote recorrió en 1757 la zona de Tierradentro y describe entre otras cosas, los usos y costumbres de los habitantes así como los sepulcros antiguos de Inzá y Pedregal. Escribió estos datos en su obra Maravillas de la Naturaleza, la cual apareció en una edición reciente de la Colección de la Presidencia de la República de Colombia, 2 volúmenes, números 28 y 29, Bogotá, 1956. Los datos que aporta son muy escasos.

\section{General Carlos Cuervo Márquez:}

Hizo exploraciones a través de Colombia. Este mismo autor nos informa que en el año de 1893 se hizo, en número reducido, apenas de 300 ejemplares, la primera edición de su obra, en la cual están agrupados escritos de naturaleza muy diferente. El viaje a Tierradentro y el estudio sobre los Paeces fueron escritos en el año de 1887, durante su permanencia en esa interesante región, en la cual permaneció varios meses. Más tarde en 1892 pudo visitar la estancia arqueológica de San Agustín (Cuervo Márquez, 1920, I : 5). Nachtigall $(1956: 22)$ dice que Cuervo Márquez menciona extraños cementerios y grandes salas subterráneas con filas de columnas y nichos; figuras humanas en piedra muy parecidas a las de San Agustín.

La obra de Cuervo Márquez fue publicada en 1893 bajo el título de Prehistoria y Viajes. En 1920, 2 tomos, Madrid, con el título de Prehistoria y Viajes: Estudios Arqueológicos y Etnográficos en 
el primer tomo y Estudios Arqueológicos y Etnográficos: Prehistoria y Viajes Americanos en el segundo.

Una última edición, 1956, Bogotá, en la Colección de la Presidencia de la República de Colombia, en un solo tomo, número 27. Los pocos datos que ofrece se encuentran en el tomo II, pp. 143-208 de la edición de 1920, Ubicación de los Páez: El Páez, vestido, habitaciones, familia, gobierno, artes, industrias, religión, idioma, etc., y un resumen etnohistórico de poco valor ya que los datos que brinda son muy esquemáticos, sin embargo los datos son excelentes para quienes quieran tener alguna idea en forma global sobre los Páez.

\section{Marqués Robert de Wavrin Villers:}

... después de informar sobre la existencia de varias estatuas nuevas, en Nariño y San Agustín, visitó en 1931 varios de estos sepulcros al pasar por Tierradentro y publicó algunos artículos sobre el particular desde 1932. Un extenso informe de sus numerosos viajes y aventuras en Colombia apareció en 1953 (Nachtigall, $1956: 23)$. No hemos podido consultar ninguna de sus obras entre las cuales se encuentran: "Contribución al estudio de la civilización llamada de San Agustín", Huila Histórico, número 1, Neiva, 1932: Chez les Indiens de Colombie, París, 1953.

\section{Doctor Georg Bürg:}

Con el doctor Bürg, geólogo alemán, en aquel entonces profesor de la Universidad del Cauca, se comienzan las exploraciones sistemáticas (1936) de las "tumbas" de Tierradentro. Una breve publicación de sus trabajos aparece en el Ibero-Amerikanisches Archiv, 1937-1938, pp. 333-375, con el título de "Beitrag zür Ethnographie Südkolumbiens auf Grund eigener Forschungen", Berlín. Como él mismo lo dice en el resumen de su escrito:

"En el artículo presente se trata de una breve descripción de la vida de sus gentes, de los indios Páez, de su historia y prehistoria. Es un estudio preliminario para la etnografía de Colombia de Sur, sobre lo cual muy poco es lo que sabemos" (p. 333). Aunque sume todo en 42 páginas, dándole bastante énfasis a la geología y geografía, de todas maneras es una fuente que debe ser consultada.

\section{Doctor Gregorio Hernández de Alba:}

Alrededor de 1937, fue enviado por el Ministerio de Educación, Dirección Nacional de Bellas Artes, para comprobar los hallazgos arqueológicos hechos por Bürg. Su informe fue publicado en dos partes en la Revista de las Indias, Vol. II, número 9 (abril), 1938 y en el Vol. II, número 10 (agosto) de 1938, en Bogotá. La primera publicación consta de 4 folios (pp. 29-32) en la cual describe los sitios excavados y las tumbas números $9,15,16,21,25,27,35,41$, 42,43 ; y 10 dibujos de los cuales siete (7) son de la decoración que tienen dichas tumbas (uno presenta el dibujo de la planta, el corte vertical y el desarrollo; otro muestra la decoración y el corte vertical y el último, la decoración, planta y corte vertical). La segunda publicación, mucho más completa y mejor ilustrada con fotos y grabados también es sobre las tumbas.

Para aquellos interesados en tumbas es de gran utilidad pues las ilustraciones son a colores, muy bien hechas y en el informe se encuentra gran abundancia de medidas con las cuales cualquiera se puede imaginar el tamaño de los nichos, peldaños, etc. y hacer una reconstrucción de las mismas. No negamos la importancia de sus datos, pues en arqueología todo detalle es importante $\mathrm{y}$, muy por el contrario, sería muy interesante que alguien trabajase en la comparación de tumbas y ver qué resultados se pueden obtener.

\section{Doctor José Pérez de Barradas:}

En octubre de 1936, este arqueólogo español, recibió el encargo del señor Ministro de Educación Nacional, de informarle sobre la importancia de los descubrimientos y excavaciones que se realizaban en Tierradentro. Hizo un resumen de las estatuas y tumbas conocidas hasta ese entonces, el cual fue publicado en 1937 por el $\mathrm{Mi}$ nisterio de Educación Nacional de Colombia, en publicaciones de la Sección de Arqueología, número 1, bajo el título de Arqueología y Antropología de Tierra Adentro. Consta de 100 páginas y 33 láminas. El libro está dividido en cinco partes:

1. Historia de las investigaciones arqueológicas.

2. Los hallazgos arqueológicos.

3. Estudio preliminar de las culturas prehistóricas de Colombia.

4. Las culturas prehistóricas de Tierradentro.

5. Cráneos antiguos deformados, de Belalcázar y Araújo. (Sitios en Tierradentro).

Menciona y describe el contenido de varios sepulcros, pero nadie se puede hacer la idea de cuáles son, pues al igual que Hernández de Alba, no los ubica en un mapa. 
La cronología establecida por Pérez de Barradas será discutida más adelante, motivo por el cual omitimos detalles.

Por lo que sí merece la pena el trabajo de este autor es por las ilustraciones que presenta al final del libro, por lo demás, el autor y con justa razón se dedica a las "tumbas" para lo que fue comisionado. En el Vol. I, número 5 (marzo), 1937, Bogotá, en la Revista de las Indias, aparece otro artículo suyo "Máscara de Oro de Inzá". Dice “... no dudará de que la máscara que estudiamos pertenece a la cultura de San Agustín, de la cual hay en Tierra Adentro numerosas estatuas y sepulcros pertenecientes a su fase epigonal" (1937: 4). Al final de este corto informe discute el objetivo de las máscaras entre diversas culturas.

\section{Licenciado Eliécer Silva Celis:}

A fines de 1942 y principios de 1943, acompañado del Licenciado Graciliano Arcila Vélez, visitó la región, en una comisión dirigida por el doctor Gregorio Hernández de Alba. Sus trabajos de reconocimiento y estudio incluyeron zonas dentro y fuera de los límites geográficos de Tierradentro. Su informe fue publicado en la Revista del Instituto Etnológico Nacional, Vol. I, $1^{\mathrm{a}}$ y $2^{\mathrm{a}}$ entrega, 1943-1944, Bogotá.

También hace descripción de varias tumbas por él excavadas pero a diferencia de los autores anteriormente mencionados, sí hace una descripción de la cerámica encontrada en las tumbas y presenta algunas ilustraciones con las cuales se pueden hacer comparaciones con la cerámica de sitios de habitación humana. El trabajo es bastante completo y bien hecho.

\section{Doctor Horts Nachtigall:}

Este arqueólogo alemán, quien visitó la región durante cuatro meses, publica los resultados de su trabajo con el título de Tierradentro: Archäologie und Ethnographie einer kolumbianischen Landschaft, en 1955. Aparece como el segundo fascículo de las publicaciones del Instituto de Etnología de la Universidad de Mainz (Maguncia). Describe sus excavaciones en el Alto de San Andrés, Filo del Aguacate, El Canadá y Segovia. Resume sus puntos de vista sobre las tumbas, su decoración, cerámica y otros, así como diferentes sitios arqueológicos, según los trabajos de sus antecesores. En Segovia, ha sacado a la luz del día muchas tumbas, de las cuales dos que él designa como números 10 y 11 , contenían abundante cerámica. El resto del libro, casi las $2 / 3$ partes está consagrado a. la etnografía de los indios Páez. Ilustrado con numerosas fotos y planos.

Otra publicación suya, "Tierradentro" en la Revista STVDIA, Revista de la Universidad del Atlántico, Vol. I, No 10, pp. 21-55, Barranquilla, 1956, es un extracto del original, traducido del alemán al español por el profesor Walter W. Koehller B., con revisión de STVDIA. Se esboza en esta publicación: el territorio, la arqueología de Tierradentro, descripción cultural del sitio (Tierradentro), las tumbas, la decoración (de las tumbas), tipos de entierro, cerámica y otros, de la cultura arqueológica de Tierradentro.

Aunque adolece de fallas como las que señala Henri Lehmann (1959) y Helmut Ziegert (1962 - 1966), es una obra seria y sobria.

Todo el énfasis de los diferentes investigadores en esta zona se ha concretado únicamente a la descripción o excavación de tumbas y muy poco a su contenido cultural. También ha llamado mucho la atención la estatuaria lítica, a la cual se le ha buscado parecido con la de San Agustín, pero no existe un estudio a fondo, confiable y verdaderamente comparativo. No negamos la importancia de las tumbas, pero debemos tener en cuenta que un pueblo no solo se dedica a hacer tumbas, hay que estudiar los otros aspectos de la cultura.

Fechas de Carbono 14 no existen hasta el momento para poder establecer una cronología. Una de las cronologías que existen hasta la fecha es la establecida por José Pérez de Barradas y la cual resumimos a continuación para conocimiento del lector:

1. Cultura epigonal de San Agustín:

Estatuas y sepulcros del Hato, Marne y Rodeo, Estatuas y sepulcros del
Siglos vil a IX d. j. c.

2. Cultura del Cauca en su fase floreciente: Sepulcros pintados del Aguacate o Loma Alta San Andrés y Segovia

3. Cultura del Cauca Reciente: Sepulcros de Belalcázar, etc. Siglos XII a xiv d. j.c.

4. Cultura Páez: Sepulcros del Alto del Grillo.
Siglos XIV d.j. c., en adelante.

(1937b: 51 - 52).

Esta cronología está basada en comparaciones estilísticas entre la estatuaria lítica de Tierradentro y San Agustín; entre los sepulcros de Tierradentro con dos citados por Luis Arango (uno de ellos de la Necrópolis de La Soledad y el otro de la Necrópolis de El Santuario, ambos en el Quindío [Caldas], actualmente Depar- 
tamento del Quindío) así como con el aumento o disminución de los colores en la decoración de las tumbas.

Es lamentable que no hiciera excavaciones estratigráficas, no da fechas absolutas (tampoco lo haremos nosotros debido a la pérdida de nuestras muestras de carbón) ni trata su material estadísticamente. Su cronología es muy intuitiva, por lo que no puede servir de base para una cronología real.

Otro intento para establecer una cronología es el de Patterson (1965: 66 - 73). Establece una secuencia cerámica para Tierradentro y San Agustín pero es más medido en sus aseveraciones. Es una buena secuencia la que establece este arqueólogo norteamericano basándose en la cerámica.

Los libros consultados son los únicos que existen sobre la región y que consideramos básicos para la arqueología de Tierradentro no obstante que la mayoría de ellos tratan sobre tumbas, destro, no obstante que la mayoría de ellos tratan sobre tumbas, des-
cripción de su contenido e ilustraciones perfectas y comparaciones estilísticas básicamente con la estatuaria lítica de San Agustín. Muy poco o casi nada es lo que hacen referencia a la cerámica de sitios de habitación pues no la hay, excepto una excavación que hizo el doctor Julio César Cubillos en El Tablón (no tenemos informes de otros sitios por él excavados) y cuyo resultado no ha publicado todavía.

Esto es lo que sabemos de la Arqueología de Tierradentro, lo cual no da pauta para que se pueda establecer una cronología con bases firmes, tal como lo quiso hacer especialmente José Pérez de Barradas. No obstante merece crédito por ser el primero en tratar este aspecto.

Haciendo un breve resumen, podemos decir que lo único que se ha hecho es sepulturología, gran énfasis en lo monumental y llamativo del cual tampoco pudimos escaparnos nosotros y ningún énfasis en sitios de habitación, por ende hemos encontrado problemas en tratar de establecer más relaciones y comparaciones pues hemos comenzado de la nada.

\section{DESCRIPCION DE LOS SITIOS EXCAVADOS}

(Véase mapa de Tierradentro)

\section{San Andrés de Pisimbalá}

El actual pueblo de San Andrés de Pisimbalá, que es parte de la Parcialidad de San Andrés, está situado en una sección de lo que pudo haber sido un sitio de habitación humana. Se encuentra a una elevación media al final del Valle del mismo nombre, entre las quebradas de San Andrés y la Virgen. Superficialmente se encuentran tiestos en la mayor parte del área, incluyendo el actual cementerio católico, los terrenos alrededor de la Iglesia y la pista de fútbol.

En nuestras investigaciones en este pueblo y especialmente por la parte más al norte y detrás de los terrenos de la iglesia, en los cuales nos habían informado de existencia de afloramientos de tiestos por el camino, pudimos constatar que esto es cierto, pero la cantidad era mínima y la profundidad, después de haber hecho varios sondeos de prueba, era de aproximadamente $35 \mathrm{cms}$., observando a la vez que la capa superficial (humus) es gruesa, mayormente raíces hasta una profundidad de aproximadamente 15 centímetros, lo que daría en realidad una profundidad de $20 \mathrm{cms}$. de concentración de tiestos, motivo por el cual no hicimos ninguna excavación pero sí algunas pocas colecciones de tiestos que se encontraban en la superficie, bastante pequeños y erosionados.

\section{$E l \quad T a b l$ ó $n$}

Esta es una meseta natural situada a la margen izquierda de la quebrada de San Andrés y la de Chapequiz y a un kilómetro y medio del pueblo de San Andrés.

En esta meseta ocupada por vegetación herbácea, algunos arbustos y árboles generalmente garrochos, se encuentran restos de huaquería (grandes zanjas) y varias estatuas de roca granodiorítica, las cuales estaban caídas en el suelo hasta que este sitio fue anexado al Parque Arqueológico de Tierradentro, con lo cual las estatuas fueron levantadas y cimentadas formando un círculo en la parte más alta y plana del sitio.

Hay que anotar también que no todas las estatuas que actualmente se encuentran aquí, fueron halladas in situ y aún más, algunas encontradas en el Pueblo de San Andrés fueron trasladadas a El Tablón.

Algunos tiestos se encuentran dispersos por toda el área; sin embargo, la zona de máxima concentración de cerámica se encuentra cerca de las estatuas en un área muy limitada.

El sitio se puede dividir en dos partes: una superior, relativamente nivelada, área de mayor elevación y donde están localizadas las estatuas, y la otra, inferior, es baja y algo pendiente.

El área alrededor de las estatuas tiene una capa de humus muy delgada y más bien parece grama siguiendo inmediatamente, debajo, el piso de piedra. 
Parte del sitio, especialmente al norte y oeste de las estatuas, es donde se nota más la actividad de los huaqueros. Esta fue hecha probablemente durante el tiempo colonial; las excavaciones son in tensas y profundas y los huaqueros actuales las atribuyen a los españoles.

La pendiente baja está ocasionalmente erosionada por los pequeños cauces o arroyos que se alimentan durante la época de lluvia y corren por ella. Sin embargo, se pueden observar algunas partes no erosionadas por estar un poco más altas.

\section{E $l \quad V \circ l a d \circ r$}

Está situado en el centro del Valle de San Andrés, a una elevación muy baja (a aproximadamente dos metros sobre la carretera). Todo este terreno que probablemente era un sitio de habitación, fue cortado cuando se construyó la carretera que va desde El Crucero hasta el pueblo de San Andrés, pero quedó suficiente terreno como para que pudiésemos abrir un pozo y obtener algún material cerámico.

Actualmente toda esta faja de terreno está dividida en varias parcelas de tierra, una de las cuales pertenece a la señora Eduvina, quien muy gentilmente nos permitió hacer la excavación en su terreno, la cual emplazamos cerca de la carretera.

Esta parcela se utiliza únicamente para cultivar maíz en medio de la hierba, que nace con profusión en todo este sitio que a la vez es muy húmedo y plagado de mosquitos. Todavía quedan algunos árboles que se han salvado de ser talados.

\section{El $\quad M a r n e$}

Se encuentra este sitio de habitación humana en una saliente, relativamente plana con leves ondulaciones del terreno, mirando hacia el río Ullucos, en el centro del Valle de Inzá. Toda esta saliente pertenece a la finca del señor Víctor Chavalo, quien tiene plantaciones de caña de azúcar y café rodeando esta faja de terreno por dos lados: norte y este, quedando los otros puntos limitando con el río Ullucos y sin cultivar.

Como sitio de defensa es excelente ya que está protegido en dos lados por el cañón del río Ullucos y en otros dos, por una baja colina que dividía antiguamente el valle del Ullucos del Páez, la cual está actualmente cortada por un camino que conduce a Inzá.

En este sitio se encuentran algunas estatuas de piedra, así como tiestos superficiales. Las estatuas de piedra, algunas ya des- critas en la literatura, están actualmente concentradas en un área baja, hacia el noroeste de la casa de los dueños de la finca, excepto una que está localizada hacia el sur de la casa y hacia el cañón del río antes mencionado. Existen algunos arroyos a lo largo del sitio, los cuales generalmente contienen agua así como algunos estanques debido al pobre drenaje del sitio; la tierra está siempre húmeda y la diferenciación de los niveles naturales del terreno es muy pobre.

A diferencia de El Tablón, la concentración cerámica no se eneuentra en un sitio específico sino dispersa; la profundidad de los pozos excavados también varía indicando de esta manera que las casas estaban también dispersas y que no hubo una densa ocupación.

\section{$E l \quad R$ o d e o}

Tal como lo dice José Pérez de Barradas (1937: 17), así se llama un llano situado en la margen derecha de la quebrada de San Andrés, ya en las proximidades de la desembocadura en el río Ullucos, que es propiedad de Luis Narváez.

Podemos agregar que está situado al oeste del pueblo o caserío de El Rodeo y según los moradores del pueblo, este sitio pertenece a la comunidad, es tierra comunal. No está cercado con alambre, excepto las franjas de terreno que tienen propietario.

Por toda esta zona afloran tiestos, especialmente cerca de un gran charco al lado de un sendero que conduce a las orillas del río Ullucos, y sin embargo el pozo número 1 que excavamos cerca de este charco no dio tan buenos resultados como el pozo número 2 , algo distante del número 1.

Tanto este sitio como El Marne, son terrenos bastante planos y con muy leves ondulaciones de terreno; son excelentes como sitio de habitación así como lugares de defensa o por lo menos desde donde se puede divisar ampliamente el panorama; son lugares muy estratégicos.

\section{EXCAVACIONES EN TIERRADENTRO}

\section{$E l \quad T a b l$ ó $n$}

Nuestros primeros pozos: 1, 2, 3, en forma de " $L$ ", cada uno de $1.5 \mathrm{~m}^{2}$, fueron excavados en una parte plana de la pendiente baja, al sur de los restos de la trinchera que abrió Julio César Cubillos 
en años pasados. Los pozos 1 y 3 produjeron muy pocos tiestos y su profundidad máxima fue de $40 \mathrm{cms}$. Del pozo $\mathrm{N}^{9} 1$ solo obtuvimos 259 tiestos y del pozo No 3,501 y se descartaron 131 y 325 tiestos, respectivamente, por medir menos de $1.5 \mathrm{~cm}^{2}$. El pozo número 2 , a pesar de que demarcado, no fue excavado ya que consumiría nuestro tiempo y no daría ningún rendimiento de valor cultural. Por otro lado podemos asegurar que estos tiestos no fueron redepositados o provenientes de la excavación del señor Cubillos.

El pozo número 4 fue colocado en una sección más alta y no muy lejos de los pozos 1 y 3 , hacia el este y cerca de la quebrada Chapequiz. Al igual que los dos anteriores, su contenido fue muy escaso y su profundidad nuevamente fue de $40 \mathrm{cms}$. El pozo número 5 al noroeste del círculo de las estatuas y cerca del borde de la quebrada Chapequiz, también produjo los mismos resultados que el pozo número 4 y su profundidad también fue de $40 \mathrm{cms}$.

Los tiestos eran tan escasos que comenzamos un reconocimiento sistemático del sitio con la ayuda de la media caña. Este instrumento hace unas perforaciones de $5^{\prime \prime}$ de diámetro hasta una profundidad de 3 o más metros si es necesario (todo depende de la vara que se le engaste). La muestra de tierra queda compactada dentro del tubo de la media caña así como cualquier objeto o material que se encuentra en el subsuelo. Pudimos hacer una prueba cada $15 \mathrm{mi}$ nutos y en dos días todo el sitio fue reconocido perfectamente. Marcanos en nuestro mapa de curvas de nivel de El Tablón el área de máxima concentración cerámica y luego excavamos los pozos de acuerdo con el resultado de nuestros cateos.

Los pozos del 6 al 11, en forma de " $L$ " se demarcaron en un área restringida, al suroeste del círculo de las estatuas, pero que era la única que contenía más cerámica y cuya profundidad dio un promedio de 100 centímetros $(1 \mathrm{~m}$.) ; podemos asegurar sin duda alguna que no existe cerámica en este sitio a una profundidad de más de 1 metro.

Todos los pozos fueron excavados por niveles artificiales excepto los números 9 y 11, que pudimos aislar del 8 y 10 .

\section{E $l \quad V$ o $l$ a d 0 o}

En este sitio solo excavamos un pozo de $1.5 \times 2$ metros, en una pendiente que mira hacia la carretera que va a San Andrés de Pisimbalá.

El pozo resultó ser relativamente profundo $160 \mathrm{cms}$. $(1.60 \mathrm{~m}$. y se excavó por niveles artificiales de $20 \mathrm{cms}$. Se hizo un mapa de curvas de nivel pero no se excavó ningún pozo adicional, ya que como dijimos anteriormente, parte del sitio fue destruído con la construcción de la carretera.

\section{$E l \quad M a r n e$}

Se excavaron siete pozos no muy separados uno de otro ya que las pruebas que hicimos para localizar zonas de máxima concentración cerámica así lo exigió.

Antes de delimitar cualquier pozo, hicimos aproximadamente 25 cateos, nuevamente con el auxilio de la media-caña. De los cateos hechos, sólo siete prometían una profundidad media de $80 \mathrm{cms}$. de acumulación de material cultural, por lo cual sólo se excavaron estos siete pozos. También hicimos un mapa de curvas de nivel sobre el cual localizamos los pozos excavados.

La excavación, también aquí, se hizo por niveles artificiales de $20 \mathrm{~cm}$. En un principio se pensó en hacer las excavaciones por estratos naturales durante nuestras excavaciones, pero para conocer el terreno era necesario abrir un pozo y excavarlo por niveles artificiales. Este pozo demostró que la estratificación física natural era difícilmente observable, ya que la tierra mantenía el mismo color debido a la concentración de la humedad mantenida constante por las lluvias y por los ojos de agua (agua subterránea) que se forman o brotan generalmente entre los 80 y $100 \mathrm{cms}$. de profundidad, y por el mal drenaje del terreno, por lo cual se prosiguió por niveles artificiales. Se trabajó en el lodo y bajo la lluvia en algunas ocasiones.

En este sitio tuvimos más suerte ya que en nuestra semana de permanencia aquí, tuvimos dos días completos de sol; las mañanas templadas y húmedas y con poco sol pero los demás días fueron de lluvia intermitente, entre la 1 y 4 de la tarde.

\section{$E l \quad R \circ d e o$}

En este sitio excavamos un pozo de $1.5 \mathrm{~m}^{2}$. al lado del estanque que está cerca del camino, el cual ya mencionamos anteriormente para este sitio y cerca del cual encontramos gran cantidad de tiestos superficialmente. Sin embargo, la profundidad de este pozo no fue muy grande, la máxima concentración de tiestos se hallaba no muy debajo de la superíicie y la profundidad no excedió de $60 \mathrm{cms}$. pero los tiestos se encontraron solo hasta los 40 centímetros.

También en este sitio hicimos otros tantos cateos con la mediacaña, la mayoría de los cuales eran poco profundos a excepción de 
un área muy reducida, donde excavamos nuestro segundo pozo de $1.5 \mathrm{~m}^{2}$ hasta una profundidad de $100 \mathrm{cms}$. $(1 \mathrm{~m}$.). La colección obtenida en este segundo pozo fue grande, alcanzándose un total de 18.242 tiestos de los cuales se descartaron 5.220 por ser menores de $1.5 \mathrm{cms}^{2}$. En cuanto al contenido de cerámica fue el mejor que encontramos en nuestras excavaciones en Tierradentro.

\section{PROCESO DE EXCAVACION}

Todas nuestras excavaciones se hicieron a base de niveles artificiales de $20 \mathrm{cms}$. con excepción de los pozos 9 y 11 de El Tablón, que se hicieron por niveles naturales.

Después de delimitar los pozos, excavamos cada nivel, se limpió y niveló el piso, se extrajeron los fragmentos de cerámica y piedras atribuyéndolas a sus respectivos niveles cuando era posible determinarlo, pero por lo general se desecharon para evitar confusión. Se verticalizaron las paredes y se limpió por completo el corte antes de iniciarse la excavación del siguiente nivel. Todo el material excavado: tierra, material cultural y piedras naturales, se depositaron aproximadamente a un metro de distancia del borde de la exeavación, de tal manera que hubo la máxima garantía de que ningún material se cayera o deslizara posteriormente dentro del pozo; además cada nivel de tierra excavado se depositó por separado para poder buscar y revisar, sin confundir, cualquier material cultural que se escapó de las manos de los trabajadores.

La tierra excavada fue escogida a mano por los trabajadores y todo el material cultural, incluyendo el fragmento más pequeño de cerámica fue empacado por uno de nosotros (Juan Yángüez), en bolsas de lienzo con su respectivo rótulo, luego amarradas con hilo de cáñamo y finalmente trasladadas al Hotel del Parque Arqueológico de Tierradentro.

En cada sitio donde excavamos, los pozos se dejaron abiertos esperando a que hubiese algo de sol para que se redujese la humedad y así poder observar y tomar las medidas de la estratificación física natural.

Una vez en el Parque, el material cerámico fue lavado, secado y empacado en bolsas, en perfectas condiciones, rotuladas por la señora Lutie de Long para su ulterior viaje a Bogotá

\section{DEMARCACION DE LOS POZOS}

Cada pozo se delimitó con dos estacas enterradas en cada una de las esquinas, formando con el cruzado de los hilos que se habían atado a cada una de ellas, el tamaño del pozo según nuestros deseos, $1,5 \times 1,5$ o 1,5 $\times 2 \mathrm{mts}$., con lo cual se evitó que al excavarse el pozo con las dimensiones antes mencionadas, se pudiesen caer las marcas dentro del pozo y perder así el control de las paredes y deformar el pozo si solo hubiésemos enterrado las marcas delimitando exactamente el tamaño de los pozos; con esto sólo utilizamos otro criterio distinto al utilizado por muchos arqueólogos y quienes no han tenido problemas, pero nosotros quisimos evitar cualquier percance. Uno es tan bueno como el otro, sólo es cuestión de escogencia.

Como punto de referencia se tomó la parte más alta del lugar donde se limitó el pozo (el cual tomamos como esquina de control) y con un nivel de burbuja colocado sobre una pita (cuerda) la cual a su vez estaba atada a la esquina más alta (la de control), se prosiguió a controlar los niveles acercando el nivel de burbuja a una medida que tenía marcada los niveles de 20 en 20 centímetros.

Para la cantidad de fragmentos cerámicos de los pozos de los diferentes sitios, véase el anexo $\mathrm{V}$ al final de este informe.

\section{EL MATERIAL}

La casi totalidad del material cerámico consiste en fragmentos bastante rotos, pequeños y en su gran totalidad, carentes de decoración. Están bastante, por no decir muy, erosionados. Sin embargo algunos fragmentos se conservan en perfectas condiciones especialmente los de El Rodeo, pozo número 2.

A simple vista son muy pocos los rasgos distintivos que se observan, más bien parece una masa de fragmentos de superficie áspera, con una cocción deficiente. En todo este conglomerado de fragmentos rotos se pueden diferenciar tres tonos de color distintivos (rojo, gris y negro); por otro lado, una vez que todos los fragmentos están expuestos en una mesa, es muy difícil distinguir los de El Tablón de los de El Volador o Marne o Rodeo con la excepción de algunos tipos que solo ocurren en El Rodeo, en donde se nota la mayor concentración.

Hubiéramos querido hacer un análisis mineralógico de los tipos de tierra que se encuentran en la región para ver su relación con la pasta de las vasijas pero fue imposible. 


\section{Téonica de laboratorio}

La rotulación de la cerámica tomó un mes y se descartaron aquellos fragmentos menores de $1.5 \mathrm{~cm}^{2}$ (véase anexo $\mathrm{V}$ ). Cada fragmento llevaba escrito: el sitio, pozo y nivel, i.e. El Rodeo, Pozo 2 , nivel $60-80$ sería: $\mathrm{R}-2,60-80$.

El material cerámico, después de constantes ensayos tipológicos, utilizando los elementos culturales de algún valor, fue clasificado con mucho celo, basándonos en la textura, color, compactibilidad de la pasta, inclusiones, decoración, baño, forma de la vasija, relaciones entre bordes, variaciones en la cocción, dureza y uso de las vasijas (sobre algunos de estos criterios hay fuertes críticas, e.g. color y dureza).

Una vez hecha la tipología tentativa, se hizo un cuadro de seriación estilo Ford, principalmente para el sitio de El Marne (fue el primero que se analizó), para tener una idea del avance y seguridad de nuestro trabajo, excepto para los pozos 2 y 3 que por ser muy escasos los fragmentos no se hizo. En el transcurso de la elaboración del resto del material arqueológico, se descartó la seriación Fordiana por ser difícil de usar, pero seguimos la clasificación con base a los elementos antes mencionados. De aquí pasamos a la descripción de cada tipo cerámico y al dibujo de los bordes, tiestos decorados y reconstrucción de algunas vasijas hasta donde fue posible.

De cada tipo cerámico se examinó una muestra, del material disponible, bajo un microscopio binocular y con una lupa de mano. Se trituró aproximadamente un centímetro cúbico de cada tipo. Se lavó el polvo en un tubo de ensayo hasta que se obtuvo un residuo mineral, el cual, una vez secado, fue examinado nuevamente bajo el microscopio para establecer cantidad, color y forma, así como medidas de las inclusiones. Las inclusiones (residuo mineral) se midieron con un lente provisto de una escala para establecer su tamaño, las cuales fueron clasificadas en:

Pequeñas: de 0.10 a 0.25 milímetros de diámetro. Medianas: de 0.25 a 0.50 milímetros de diámetro. Burdas: de 0.50 a 1 milimetro de diámetro.

Los colores se determinaron con la ayuda del Dictionary of Colors de Maez \& Paul (edición 1950) por no contar con otro más moderno como Munsell Color Chart, en caso de que el color tenga alguna validez. Para la determinación de la dureza se utilizó la Escala de Moh. El espesor se midió con un compás de corredera, graduado, y para la descripción general de la cerámica se utilizaron los crite- rios sugeridos por Ann O. Shepard (1965) y modificados por el doctor Gerardo Reichel-Dolmatoff.

Hemos utilizado el criterio clasificatorio del doctor ReichelDolmatoff, para facilitar la comparación con trabajos suyos ya publicados. Es solo una cuestión práctica y de facilidad y no por sentimentalismo o escuela.

\section{LOS TIPOS CERAMICOS}

Los tipos por nosotros establecidos son los siguientes:

GRIS :

Tavomaro gris sencilla,

Tavomaro gris lisa,

Tavomaro gris pulida,

Tavomaro gris bañada,

Tavomaro gris con capa.

$R O J A$

Tavomaro roja sencilla,

Tavomaro roja lisa,

Tavomaro roja bañada,

Tavomaro roja tosca.

$N E G R A$ :

Tavomaro negra sencilla, Tavomaro negra lisa,

Tavomaro negra pulida,

Tavomaro negra bañada,

Tavomaro negra con capa.

Tavomaro modelada acanalada,

Son esencialmente tipos de cocina, servicio, almacenamiento y algunos tipos intrusos como Tavomaro modelada acanalada y $T$ Tavomaro crema sencilla.

Todos estos tipos, principalmente gris sencilla, roja sencilla y negra sencilla se presentan invariablemente en todos los sitios, motivo por el cual no duplicamos la nomenclatura ni la descripción de cada sitio y pozo y mejor incluímos el anexo $\mathrm{V}$ con la distribución de cerámica por pozo y nivel con excepción de El Marne. Hay unos tipos que solo ocurren en algunos sitios, i. e. Modelada acanalada (Marne, pozo 4; 2 fragmentos en el nivel $20-40$ y 3 en el nivel 40-60) ; roja tosca (solo en El Rodeo, pozo 2), gris y negra con capa (solo en El Rodeo, pozos 1 y 2) y la crema sencilla (El Marne, pozos 4 y 6 ). 
No se observa en la nomenclatura, El Tablón: gris sencilla, El Volador: gris sencilla, El Marne: gris sencilla, etc., sino el nombre Tavomaro que corresponde a las dos primeras letras de cada uno de los sitios que excavamos (Tablón, Volador, Marne y Rodeo). Pudimos haber escogido el nombre de Tierradentro gris sencilla pero esto implicaría el haber hecho excavaciones en toda la región, que los tipos por nosotros establecidos son los únicos de la región y que Tierradentro no es más que una pequeña región cultural, lo cual no es cierto, porque no sabemos hasta dónde se extendió o recibió influencia.

En un principio, tal como se mencionó en páginas anteriores, se utilizó la seriación Fordiana, pero se descartó más tarde porque la figura que presentaba era errónea e ilógica, ya que en un nivel donde existe mayor cantidad de un tipo, i. e. roja sencilla, gris sencilla, etc. y pocos fragmentos, i. e. roja bañada, al obtener el porcentaje horizontal para este último tipo, resulta ser dos o tres por ciento, cuando en la secuencia vertical su aparición tiene sentido, y por otra parte, en un nivel donde se encontró un tiesto, éste represente el $100 \%$ de este nivel, lo cual no puede ser posible. Aún más, esta seriación depende en la cantidad de fragmentos que uno tenga y si no hubiese descartado los menores de $1.5 \mathrm{~cm}^{2}$. (77.654) hubiéramos tenido otra figura.

Otros principios de seriación, basados en decoración no fueron utilizados, pues la cerámica de los sitios que excavamos no es decorada. Ilustramos todos los fragmentos incisos (decorados), encontrados en nuestras excavaciones y la única pauta que se puede observar son puntos, líneas y una combinación de ambos, pero nuestra muestra es muy pequeña para sugerir una evolución temporal.

El criterio de formas es evidentemente el mejor pero surge un problema cuando se trata de establecer el porcentaje de formas de vasijas y su evolución, pues es necesario hacerlo basándose en el tamaño, espesor y cantidad de bordes. Habrá que preguntarse: cuántos bordes son de una misma vasija, lo cual nos daría una figura diferente que si se pudiesen agrupar todos los bordes con su respectiva vasija. La mayor parte de nuestros bordes corresponden en nuestras ilustraciones al 54 con sus variantes (este borde predomina en la roja sencilla).

En nuestro caso, lo que hemos hecho es establecer una tipología tentativa basada en 'tipos' sujeta a una futura revisión (debemos aclarar que ésta no es la última palabra en la arqueología de Tierradentro), una descripción cerámica lo más completa posible y reconstrucción de vasijas basándonos en algunos de nuestros bordes más completos, en partes de vasijas con su respectivo cuerpo que pudimos recuperar y por comparaciones con otras formas encontradas enteras, especialmente en Pedregal y en las tumbas de Tierradentro de Segovia y Necrópolis de la Montaña y con las formas ilustradas por Pérez de Barradas (1943). Los tipos cerámicos probablemente pueden agruparse en algunos casos y sería lo más lógico, pero necesitamos más excavaciones antes de poder decidir sobre el particular.

\section{RESUMEN DE LAS FORMAS}

$V A S I J A S$ :

Platos pandos con boca ancha y bordes gruesos.

Ollas grandes para almacenar o cocinar bebidas (chicha)

Vasijas con doble vertedera y asa en forma de puente.

Botellas de boca restringida.

Trípodes con pies macizos.
Vasijas pedestal con base troncónica (un ejemplar)

$B O R D E S$ :

Gruesos redondeados con gran variación.

Gruesos y delgados rectos.

Gruesos con plataforma.

Gruesos altamente

UERPO:

Globular.

Sub-globular.

Con ángulo periférico.

Recto.

$B A S E S$

Planas (raras)

Redondeadas (comunes).

\section{COMPARACIONES}

Las pocas comparaciones que haremos, serán básicamente con el mismo sitio de Tierradentro, San Agustín, Momil y Tumaco, por ser regiones más o menos cercanas o dentro de un radio de posible influencia.

En la Necrópolis de la Montaña, una serie de potreros situados en la parte alta y a $3 \mathrm{~km}$. N. E. de San Andrés de Pisimbalá, Silva Celis (1943-1944) excavó dos tumbas y describe e ilustra la cerámica de dichas tumbas en las figuras 9 y 10 , respectivamente (hay más ilustraciones, sólo estas dos nos interesan). 
En nuestros sitios encontramos formas de vasijas (pudimos hacer algunas reconstrucciones) idénticas a su figura número 9, dibujos 1,2 y 4 , que son ollas.

Las descripciones suyas son para el dibujo 1, figura 9: presenta un color siena quemado y ha sido taponada con una solución de arcilla de color oscuro. El material de la pasta ofrece un color ocre oscuro y corresponde a una arcilla con abundantes partículas de cuarzo y algo de mica (nuestro tipo Tavomaro roja sencilla). El recipiente fue hecho probablemente por el sistema del enroscado. Se trata de un utensilio de cocina. Su olla número 2 , figura 9 , tiene sonido metálico que indica buena cocción, y el color de fractura es de un ocre rojo homogéneo en toda la pasta. El material de ésta es una arcilla de color ocre rojo, y entre sus componentes se aprecian granos silíceos, granos ferruginosos (en nuestra descripción es óxido de hierro), y algo de mica. La vasija corresponde a un utensilio de cocina. Su olla número 4 , figura 9 , ofrece un color siena quemado, color que se acentuó un tanto con el sometimiento continuo al fuego en las necesidades domésticas. El color de la superficie interna es algo más oscuro que el de la externa. La vasija es de forma semiesférica con un suave achatamiento en la base. Cuello bajo, doblado sobre sí mismo hasta la mitad de su altura. Se fabricó por el sistema de modelaje de pastas que sucesivamente se fueron aplicando hasta formar el recipiente, etc. Su dibujo 1, figura 10 , es un plato hondo con reborde volteado hacia afuera. Presenta buen grado de cocción. Un fino engobe por medio de una solución muy líquida de arcilla, cubre sus superficies interna y externa. En ambas caras se observa un color carmelita oscuro muy homogéneo. El cántaro fue hecho según la técnica del modelado. El cuerpo del plato se compone de un cuenco chato y esférico y una porción cilíndrica que se continúa en un reborde doblado un poco hacia afuera; su otra ilustración es un plato hondo con reborde volteado hacia afuera y parcialmente doblado sobre sí mismo (fig. 10, dibujo 2), el sonido metálico indica buena cocción. Ambas superficies muestran un fino taponado por medio de un baño de arcilla muy líquida. Como el anterior, este plato está compuesto de un cuenco chato y esférico, seguido de una porción cilíndrica que remata en un reborde echado hacia afuera y parcialmente doblado hacia abajo. (Véanse nuestros bordes: $70,71,72,74,84,121,122,123,124$ y 131).

Otra forma que encontramos también en la Necrópolis de la Montaña son vasijas trípodes. Silva Celis (1943-1944) dibujo 3, figuras 9 y 10. El de la figura 9 ha sido hecho de una arcilla de color rojo venecia y en el material se observan arenas silíceas o rodadas, lo mismo que abundantes partículas de cuarzo y mica. Las superficies interior y exterior presentan un tono rojo venecia. Manchas de ocre azul oscuro se observan en el fondo interno y externo del vaso, lo mismo que en las patas, lo cual se debió a un mayor recocimiento de la pieza en esas partes. Un suave engobe de color rojo venecia recubre un pulimento hecho con un palillo en sentido horizontal para el cuerpo y vertical para las patas. Los ondulados dejados por la aplicación del palillo en fresco varían de 3 a $4 \mathrm{~mm}$. de anchura (nosotros pensamos que son ondulaciones debido a la mano del alfarero). Aunque fue un utensilio doméstico, el vaso no muestra señales de haber sido puesto al fuego para cocer alimentos. La técnica de fabricación que se siguió en la pieza fue la de la aplicación de bandas en espiral y luego alisadas. Las patas o pies se hicieron mediante el modelado, etc. La descripción de la figura 10 es parecida o idéntica a la de la número 9.

Nachtigall (1955, lámina LXVI, figura 97) también ilustra una vasija trípode igual a las de Silva Celis y a las nuestras (no las ilustramos: sólo encontramos pies).

En El Marne, pozo 2 (véase Mapa de Curvas de nivel de El Marne y lámina 1, figura 1: Valle de El Marne) encontramos un fragmento de borde igual al de la vasija de Nachtigall (1955, lámina LXVII, figura 106), la cual se encuentra en el Museo del Parque Arqueológico de Tierradentro (véase lámina 5, figura 3). El borde de esta olla es ondulado y fue hallado por Nachtigall en la cámara de la tumba número 11, en Segovia.

Fragmentos de vertederas fueron encontrados en El Tablón, pozo 11, estrato A (es el superior) y en el pozo VI, nivel 80-100; y en El Marne, pozo 2, nivel 80-100 y 100-120. Nachtigall (1955, lámina LXVI, figura 100) y Duque Gómez (1966, dibujo 42 en página 323 y gráfico XI, ilustración 123) ilustran estas vertederas.

Dos fragmentos de asas de forma arqueada fueron encontradas en El Marne, pozo 4, niveles 20-40 y en El Tablón, pozo 8, nivel $60-80$ y pozo 10 , nivel 40-60, cuyas ilustraciones son iguales que aquellas para los fragmentos de vertedera.

Un fragmento de agarradera u oreja fue hallado en El Marne, pozo 6, nivel 60-80 y otro en El Rodeo, pozo 2, nivel 0-20 ilustradas por Nachtigall (1955, lámina LXVI, figura 101).

Los fragmentos modelados acanalados de El Marne, pozo 4, niveles 20-40 y 40-60 se comparan con los de Duque Gómez (1966, gráfico IX) y parecidos a su cerámica corrugada (Lámina XII, ilustración 8) aunque no se aprecian mucho los detalles. 
Los bordes decorados incisos son iguales a los de Duque Gómez (gráfico I, número 8; gráfico III, números 31 y 32 ; gráfico IX, número 97), estos bordes los hallamos en El Tablón 11, nivel A y en El Rodeo, pozo 1, nivel 0 -20.

Un borde con una especie de hachurado (cross-hatching) fue encontrado en El Marne, pozo 4, nivel 20-40, también en El Rodeo, pozo 2, nivel 40-60 y en El Tablón, pozo 7, nivel 40-60 es igual al de Duque Gómez (1966, gráfico IV, número 44).

Los bordes ilustrados por Duque Gómez (op. cit. gráfico V, números 52 y 59) fueron hallados en El Tablón, pozo 7, nivel 20-40. Otro ilustrado en el gráfico VI, número 64, lo encontramos casi exclusivo en nuestro tipo gris sencillo (véanse nuestros bordes 85 , $86,87,88,96$ y 97 ). Su borde número 51 , gráfico $\mathrm{V}$, son los números $55,56,60,63,75,125,126$ y 127 de nuestras ilustraciones de bordes. En el mismo gráfico, el número 55 corresponde a los bordes de nuestra roja tosca.

Tiestos con peloticas aplicadas, igual al gráfico IX, dibujo 101 de Duque Gómez (op. cit.), los encontramos en nuestro borde 107 y en algunos fragmentos con appliqué de El Tablón.

La mayoría de los fragmentos incisos estaban rellenos de pasta blanca, muy característico de la cerámica incisa con relleno blanco de las tumbas.

El fragmento con una cabeza de serpiente en alto relieve y decorado con líneas incisas, ilustrado por Silva Celis (1943-44, figura número 4, dibujo 4) excepto por el inciso punteado lateral, es igual a la que ilustramos en la cerámica de El Rodeo. Este fragmento fue encontrado en El Rodeo, pozo 2 nivel 60-80, tipo negro liso variante de la negra sencilla (?).

Un solo fragmento negro, también de El Rodeo, pozo 2, nivel 60-80 con triángulos rellenados de líneas rectas paralelas, es igual a la decoración de la vasija ilustrada por Nachtigall (1955, lámina LXXIV, figura 132) y al ilustrado por nosotros en la cerámica incisa y otros de El Rodeo.

La cerámica crema en las excavaciones en San Agustín realizadas por el doctor Reichel-Dolmatoff, aparece en todos los niveles. Lleva el número 825, San Agustín 6, cuadrícula C, nivel 5. En este mismo nivel, la cuadrícula ' $\mathrm{A}$ ' tiene una fecha de $330 \mathrm{~A}$. D. (el doctor Reichel-Dolmatoff, no ha terminado de analizar el material de San Agustín, motivo por el cual se dan todos los detalles para localizar este tipo cerámico).
Nuestro borde número 61 con todas sus variantes aparece en San Agustín 6, cuadrícula C, nivel 17. En la cuadrícula 'A', nivel 20, la fecha es 20 A. D.

Con Momil tenemos como con Tierradentro, San Agustín y Tumaco que se discutirá más adelante, los pies altos sólidos, característicos de Momil II, con un marcado hombro en la zona donde el pie se voltea para unirse luego a la pared del recipiente (ReichelDolmatoff, 1956 : 286-287).

La cerámica Momil crema, tipo bañada es fina, delgada y pertenece a formas pequeñas no culinarias, nosotros solo tenemos muy pocos fragmentos.

Finalmente, con Tumaco, Cubillos (1955: 61-62) menciona que hay dos tipos de vasijas trípodes: macizas y huecas. Las macizas acusan menos atención en el acabado y todo hace pensar que las vasijas a que pertenecieron presentaban acabados más o menos bruscos (ruestras vasijas también). En este grupo halló los fragmentos de especímenes más grandes (también nosotros). Ilustra los tipos macizos en su figura 1: A-B-C-D. El más parecido a los nuestros es el de su figura 1: A que se conserva en todos los niveles de Tumaco y es frecuente en Tierradentro; las vasijas con pies huecos no fueron encontradas en Tierradentro.

\section{I S C U S I O N}

A través de nuestras comparaciones hemos podido observar que la relación con San Agustín es muy estrecha, más que con cualquier otro de los sitios con los cuales hemos hecho comparaciones.

En este momento, aunque no es el más propicio, debemos mencionar que el material obtenido de nuestras tumbas (Anexo VI) es idéntico a los hallados en las otras tumbas de la región y por ende se relaciona con la cerámica de nuestros sitios de habitación.

Volviendo a nuestro tema, tenemos que las formas y pies de las vasijas trípodes, esencialmente sólidas son idénticas a las de los otros sitios ya discutidos o comparados, así como los platos anchos, pandos con labios salientes y bases generalmente redondeadas (lámina 5). Los bordes se duplican tanto en su mayoría en Tierradentro como en San Agustín.

El doctor Reichel-Dolmatoff (1965: 94-95) al referirse a San Agustín, dice que el doctor Duque Gómez ha propuesto tres períodos culturales [para San Agustín] basándose en el Complejo Mesitas.

...the earlier period, lasting more or less from $555 \mathrm{~B} \mathrm{C}$ to $\mathrm{AD}$ 425, is characterized by the following elements: shaft graves with 